\title{
Multi-instrument comparison and compilation of non-methane organic gas emissions from biomass burning and implications for smoke-derived secondary organic aerosol precursors
}

\author{
Lindsay E. Hatch ${ }^{1, \mathrm{a}}$, Robert J. Yokelson ${ }^{2}$, Chelsea E. Stockwell ${ }^{2, b}$, Patrick R. Veres ${ }^{3,4}$, Isobel J. Simpson ${ }^{5}$, \\ Donald R. Blake ${ }^{5}$, John J. Orlando ${ }^{6}$, and Kelley C. Barsanti ${ }^{1, a}$ \\ ${ }^{1}$ Department of Civil and Environmental Engineering, Portland State University, Portland, OR, USA \\ ${ }^{2}$ Department of Chemistry, University of Montana, Missoula, MT, USA \\ ${ }^{3}$ Cooperative Institute for Research in Environmental Sciences, University of Colorado, Boulder, CO, USA \\ ${ }^{4}$ Chemical Sciences Division, Earth System Research Laboratory, National Oceanic and Atmospheric Administration, \\ Boulder, CO, USA \\ ${ }^{5}$ Department of Chemistry, University of California, Irvine, Irvine, CA, USA \\ ${ }^{6}$ National Center for Atmospheric Research, Boulder, CO, USA \\ ${ }^{a}$ current address: Department of Chemical and Environmental Engineering and College of Engineering - Center for \\ Environmental Research and Technology (CE-CERT), University of California, Riverside, Riverside, CA, USA \\ b current address: Chemical Sciences Division, Earth System Research Laboratory, National Oceanic and Atmospheric \\ Administration, Boulder, CO, USA
}

Correspondence to: Kelley C. Barsanti (kbarsanti@engr.ucr.edu)

Received: 7 July 2016 - Published in Atmos. Chem. Phys. Discuss.: 18 July 2016

Revised: 2 December 2016 - Accepted: 10 January 2017 - Published: 31 January 2017

\begin{abstract}
Multiple trace-gas instruments were deployed during the fourth Fire Lab at Missoula Experiment (FLAME4), including the first application of proton-transfer-reaction time-of-flight mass spectrometry (PTR-TOFMS) and comprehensive two-dimensional gas chromatography-time-offlight mass spectrometry (GC $\times$ GC-TOFMS) for laboratory biomass burning (BB) measurements. Open-path Fourier transform infrared spectroscopy (OP-FTIR) was also deployed, as well as whole-air sampling (WAS) with onedimensional gas chromatography-mass spectrometry (GCMS) analysis. This combination of instruments provided an unprecedented level of detection and chemical speciation. The chemical composition and emission factors (EFs) determined by these four analytical techniques were compared for four representative fuels. The results demonstrate that the instruments are highly complementary, with each covering some unique and important ranges of compositional space, thus demonstrating the need for multi-instrument approaches to adequately characterize BB smoke emissions. Emission factors for overlapping compounds generally com-
\end{abstract}

pared within experimental uncertainty, despite some outliers, including monoterpenes.

Data from all measurements were synthesized into a single EF database that includes over 500 non-methane organic gases (NMOGs) to provide a comprehensive picture of speciated, gaseous BB emissions. The identified compounds were assessed as a function of volatility; 6-11\% of the total NMOG EF was associated with intermediate-volatility organic compounds (IVOCs). These atmospherically relevant compounds historically have been unresolved in BB smoke measurements and thus are largely missing from emission inventories. Additionally, the identified compounds were screened for published secondary organic aerosol (SOA) yields. Of the total reactive carbon (defined as EF scaled by the $\mathrm{OH}$ rate constant and carbon number of each compound) in the BB emissions, 55-77\% was associated with compounds for which SOA yields are unknown or understudied. The best candidates for future smog chamber experiments were identified based on the relative abundance and ubiquity of the understudied compounds, and they in- 
cluded furfural, 2-methyl furan, 2-furan methanol, and 1,3cyclopentadiene. Laboratory study of these compounds will facilitate future modeling efforts.

\section{Introduction}

Biomass burning (BB) emits large amounts of trace gases, including non-methane organic gases (NMOGs) and primary (directly emitted) particulate matter (PM). NMOGs also react in the atmosphere to form secondary PM and ozone. BB PM has been difficult to represent accurately in models used for chemistry and climate predictions (Alvarado et al., 2009, 2015; Heald et al., 2011; Reddington et al., 2016), including for air quality and fire management purposes. Given the significant influence of PM on the radiative balance of the atmosphere (Hobbs et al., 2003) and on cloud formation (Desalmand and Serpolay, 1985; Reid et al., 2005), as well as on human health (Naeher et al., 2007; Tinling et al., 2016; Viswanathan et al., 2006), more accurate model representation of BB PM is needed. This is particularly true given the projected increase in fire activity globally due to increased food demand (Tilman et al., 2001) and climate change (Flannigan et al., 2009; Hessl, 2011; Westerling et al., 2006; Yue et al., 2015).

While many factors contribute to the challenge of accurately predicting $\mathrm{BB}$ PM in plumes with variable dynamics and chemistry (Herron-Thorpe et al., 2014), one significant limitation has been the incomplete identification and quantification of NMOGs emitted from fires that may serve as precursors for secondary organic PM (i.e., secondary organic aerosol, SOA) (Alvarado and Prinn, 2009; Alvarado et al., 2009; Warneke et al., 2011). Given that BB is the secondlargest source of NMOGs worldwide, the SOA formation potential from BB is large (Yokelson et al., 2008). Observations of SOA formation in BB plumes have been highly variable, with OA mass enhancement ranging from $<1$ to 4 (Akagi et al., 2012; Forrister et al., 2015; Grieshop et al., 2009; Hennigan et al., 2011; Jolleys et al., 2012; May et al., 2015; Ortega et al., 2013; Vakkari et al., 2014; Yokelson et al., 2009); such observations reflect $\mathrm{OA}$ mass lost to dilution in addition to OA mass gained due to SOA production (e.g., Bian et al., 2016). Much recent research supports that many previously unconsidered SOA precursors exist (Chan et al., 2009; Lim and Ziemann, 2009; Robinson et al., 2007) and that mechanisms beyond gas-particle partitioning of semi-volatile organic compounds contribute to ambient SOA formation, including oxidation of lower-volatility precursors (Ziemann and Atkinson, 2012; Robinson et al., 2007). More specifically, it has been demonstrated that the unspeciated NMOGs may contribute significantly to BB SOA (Jathar et al., 2014). In order to better understand and accurately model the production of BB SOA, as well as other secondary pollutants (e.g., ozone and peroxyacyl nitrates), improved identification and quantification (e.g., emission factors, EFs) are needed for all compounds/classes of compounds that can serve as SOA precursors.

In this work, the determination of previously un- and under-characterized gas-phase organic compounds and compound classes was pursued by extensive analysis and synthesis of data collected from a unique and powerful combination of techniques. This work builds on prior BB emission characterization efforts (e.g., Yokelson et al., 2013) in which high-molecular-weight NMOGs were detected, but many (30-70\% by mass) could not be identified. NMOGs emitted from laboratory biomass burns were measured during the fourth Fire Lab at Missoula Experiment (FLAME4) using open-path Fourier transform infrared spectroscopy (OP-FTIR) (Stockwell et al., 2014), whole-air sampling with 1-D gas chromatography (GC) analysis (WAS), protontransfer-reaction time-of-flight mass spectrometry (PTRTOFMS) (Stockwell et al., 2015), and comprehensive twodimensional gas chromatography-time-of-flight mass spectrometry (GC $\times$ GC-TOFMS) (Hatch et al., 2015). The data were analyzed and synthesized herein to meet the following objectives: (1) compare the compositional space and calculated EFs accessed by each instrument; (2) provide comprehensive $\mathrm{BB}$ gas-phase emission profiles for each of the sampled fuels; and (3) describe the volatility distribution of the determined compounds and identify potentially important, yet understudied, SOA precursors.

\section{Methods}

\subsection{FLAME-4 sampling}

From the FLAME-4 data sets, four burns were chosen for in-depth analysis: ponderosa pine boughs (Pinus ponderosa, burn 144, hereafter referred to as pine), Chinese rice straw (Oryza sativa, burn 153, straw), Indonesian peat (burn 154, peat), and black spruce boughs (Picea mariana, burn 155, spruce); the fuels and fires have been described previously (Stockwell et al., 2014; Hatch et al., 2015). These selected fires burned the most globally relevant fuels out of the limited number of burns where gas-phase data were available from all of the above instruments. Two burning configurations were utilized during FLAME-4: stack burns and room burns (Stockwell et al., 2014). Data included here were obtained during room burns wherein smoke from flaming and smoldering combustion mixed throughout the burn chamber. The modified combustion efficiency (MCE), a measure of the relative contributions of flaming and smoldering combustion, varied among these burns, with the MCE values of most burns reflecting the combination of flaming and smoldering emissions: 0.927 (pine), 0.933 (spruce), and 0.942 (straw). The peat emissions were dominated largely by smoldering combustion $(\mathrm{MCE}=0.832)$. The smoke was "stored" in the room for approximately $2 \mathrm{~h}$ while sampling occurred; thus 
some lower-volatility compounds were eventually lost to particles or surfaces (Stockwell et al., 2014).

Although all instruments sampled during each burn, the timing and location of each sample varied due to the sampling configuration and duration of room burns. An example of the relative sampling periods is provided in Fig. S1 in the Supplement. The OP-FTIR measured continuously throughout the burn and was located on a platform high up in the combustion chamber. For GC $\times$ GC-TOFMS, integrated samples were collected closer to the fuel source after mixing was achieved. The PTR-TOFMS sampled spatially near the GC $\times$ GC-TOFMS but often not temporally as it also sampled from two smog chambers throughout the sampling period. WAS canister samples were collected from the smog chambers, which were filled with well-mixed smoke. Although the FLAME-4 measurements were not set up for a rigorous intercomparison, and thus spatial and temporal overlap between the various techniques were not ideal, an assessment of the general agreement and the compositional space probed by each technique provides new and valuable insights.

\subsubsection{OP-FTIR}

The OP-FTIR system deployed in FLAME-4 was described by Stockwell et al. (2014). Briefly, it consisted of a Bruker Matrix-M infrared (IR) cube spectrometer with an open White cell that was positioned in a well-mixed part of the combustion room about $15 \mathrm{~m}$ above the fuel bed and $10 \mathrm{~m}$ from the other instrument inlets. The optical path length was $58.0 \mathrm{~m}$, and IR spectra were collected at a resolution of $0.67 \mathrm{~cm}^{-1}$. Sixteen interferograms were co-added to give single-digit parts per billion by volume (ppbv) detection limits at a time resolution of $6 \mathrm{~s}$ with a duty cycle greater than $95 \%$.

Mixing ratios were determined for 19 gas-phase species (and water) by multicomponent fits to selected regions of the IR transmission spectra with synthetic calibration using a nonlinear least-squares method (Burling et al., 2010; Stockwell et al., 2014). The uncertainties in the individual mixing ratios vary by spectrum and molecule and are dominated by uncertainty in the reference spectra $(1-5 \%)$ or the detection limit $(0.5-15 \mathrm{ppb})$, whichever is larger.

OP-FTIR offers numerous advantages for the analysis of BB emissions (Burling et al., 2010; Christian et al., 2004). This approach achieves simultaneous and quantitative measurement of reactive and stable species (both inorganic and organic in nature) from flaming and smoldering combustion with high time resolution. Each analyte's IR spectrum displays multiple unique features, which limits spectral interference when combined with advanced, multi-component chemometric analysis. Further, because of the open-path configuration, OP-FTIR measurements are not subject to storage or sampling losses. However, foregoing pre-concentration to preserve detection of reactive species limits quantification to compounds present at mixing ratios of several ppb or greater.

\subsubsection{WAS}

During FLAME-4, WAS samples were collected from dark smog chambers. The smog chambers were filled using Dekati ejector dilutors (Hennigan et al., 2011; Stockwell et al., 2014) situated within the combustion chamber; the smoke was diluted $\sim 25$-fold. The WAS samples were collected into evacuated $2 \mathrm{~L}$ electropolished stainless-steel canisters and analyzed at the University of California, Irvine (UCI) using multi-column $\mathrm{GC}$ to measure $\mathrm{CO}_{2}, \mathrm{CO}, \mathrm{CH}_{4}$, and approximately 70 NMOGs. Details of canister preparation for field and analytical procedures are given in Simpson et al. (2010). A background canister sample was taken prior to filling the smog chamber, and the sample of primary BB emissions was taken immediately before initiation of the chemical perturbation. $\mathrm{CO}_{2}, \mathrm{CH}_{4}$, and $\mathrm{CO}$ were analyzed separately from the NMOGs using GC with a thermal conductivity detector (TCD) for $\mathrm{CO}_{2}$, and $\mathrm{GC}$ with flame ionization detection (FID) for $\mathrm{CO}$ and $\mathrm{CH}_{4}$. NMOGs were analyzed by cryogenically pre-concentrating $217 \mathrm{~cm}^{3}$ of sample air and then vaporizing the sample with a hot water bath and splitting the air into five different streams, each directed to a different column-detector combination. These include two GC-FID combinations, two GC with electron capture detector (ECD) combinations, and GC with mass spectrometer detection (MSD). The measurement precision, accuracy, and detection limits vary by compound. The detection limit is 3 pptv for NMOGs. The accuracy is $2 \%$ for $\mathrm{CO}_{2}, 1 \%$ for $\mathrm{CH}_{4}$, and $5 \%$ for $\mathrm{CO}$ and NMOGs. The measurement precision is $2 \%$ for $\mathrm{CO}_{2}$ and $\mathrm{CO}, 0.1 \%$ for $\mathrm{CH}_{4}$, and $3 \%$ for most NMOGs (Simpson et al., 2014).

The UCI WAS collection and analysis methods have been rigorously characterized and validated (Simpson et al., 2010). The multi-column and multi-detector approach provides accurate identification and quantification for a range of speciated hydrocarbons (HCs) and some oxygenates in BB emissions (Simpson et al., 2011). In this work, organonitrates were the only oxygenates quantified; other oxygenates, such as methanol and acetone, were not quantified because of their higher measurement uncertainty (Simpson et al., 2011) especially for concentrated samples. The "grab" sampling approach limits the temporal coverage of a smoke plume, unless a large number of samples are collected. However, in this work the sampled smoke was well mixed, and therefore a single grab sample is expected to be representative of the overall emissions from all burn phases.

\subsubsection{PTR-TOFMS}

PTR-TOFMS sampling during FLAME-4 has been described in detail (Stockwell et al., 2015). Briefly, a PTRTOFMS 8000 (Ionicon Analytik GmbH, Innsbruck, Austria) (Jordan et al., 2009) sampled continuously through $1 \mathrm{~m}$ heated $\left(80^{\circ} \mathrm{C}\right) \mathrm{PEEK}$ tubing from the control room along one side of the combustion chamber. During the room burns dis- 
cussed in this work, the PTR-TOFMS sampled intermittently between two smog chambers and the combustion chamber. The mass resolution $(m / \Delta m)$ was $4000-5000$ at $m / z 21$, with a typical mass range from $m / z 10$ to 600 . The drift tube was operated at $600 \mathrm{~V}, 2.3 \mathrm{mbar}$, and $80^{\circ} \mathrm{C}(E / N \sim 136 \mathrm{Td}$; $E$ is the electric field strength, $N$ is the concentration of neutral gas, and $1 \mathrm{Td}=10^{-17} \mathrm{~V} \mathrm{~cm}^{2}$ ).

The PTR-TOFMS was calibrated every few days using a mixture of formaldehyde ( $\mathrm{HCHO})$, methanol $\left(\mathrm{CH}_{3} \mathrm{OH}\right)$, acetonitrile $\left(\mathrm{CH}_{3} \mathrm{CN}\right)$, acetaldehyde $\left(\mathrm{CH}_{3} \mathrm{CHO}\right)$, acetone $\left(\mathrm{C}_{3} \mathrm{H}_{6} \mathrm{O}\right)$, dimethyl sulfide (DMS, $\left.\mathrm{C}_{2} \mathrm{H}_{6} \mathrm{~S}\right)$, isoprene $\left(\mathrm{C}_{5} \mathrm{H}_{8}\right)$, methyl vinyl ketone $\left(\mathrm{C}_{4} \mathrm{H}_{6} \mathrm{O}\right)$, methyl ethyl ketone $\left(\mathrm{C}_{4} \mathrm{H}_{8} \mathrm{O}\right)$, benzene $\left(\mathrm{C}_{6} \mathrm{H}_{6}\right)$, toluene $\left(\mathrm{C}_{6} \mathrm{H}_{5} \mathrm{CH}_{3}\right)$, p-xylene $\left(\mathrm{C}_{8} \mathrm{H}_{10}\right)$, 1,3,5- trimethylbenzene $\left(\mathrm{C}_{9} \mathrm{H}_{12}\right)$, and $\alpha$-pinene $\left(\mathrm{C}_{10} \mathrm{H}_{16}\right)$. Separate mass-dependent calibration factors were derived for hydrocarbons and compounds that included heteroatoms to calibrate the remaining species; measurement error was estimated to be $\sim 20-30 \%$ for calibrated gases and up to $50 \%$ for uncalibrated gases (Stockwell et al., 2015). Instrument zeros were periodically performed using a precious metal catalyst.

Proton-transfer-reaction mass spectrometry uses $\mathrm{H}_{3} \mathrm{O}^{+}$based ion-molecule reactions to ionize analyte species with minimal fragmentation. Only compounds with proton affinities greater than that of water are ionized (de Gouw and Warneke, 2007; Lindinger et al., 1998). The high mass resolution of the TOF mass analyzer permits separation of compounds that are isobaric at unit mass resolution and enables assignment of molecular formulas, although this method is unable to separate isomers with the same chemical formula.

\subsubsection{GC x GC-TOFMS}

NMOG samples were collected onto adsorption-thermal desorption (ATD) cartridges, as described in Hatch et al. (2015). Briefly, cartridge samples were collected from the control room, through a Teflon inlet $<5 \mathrm{~m}$ long with the sampling tip located $\sim 2-3 \mathrm{~m}$ from the PTR-TOFMS inlet and about $1 \mathrm{~m}$ into the burn chamber. To prevent particles and ozone from reaching the sorbent, a glass-fiber filter coated with sodium thiosulfate was placed upstream of the cartridge in the sampling train (Helmig, 1997). The samples were frozen and then analyzed at Portland State University within 1 month of sampling. An ATD 400 system (PerkinElmer, Waltham, MA, USA) was used to desorb and inject each sample into a Pegasus 4D GC $\times$ GC-TOFMS (Leco Corp., St. Joseph, MI, USA). Calibration curves were determined for $\sim 275$ standard compounds; tentatively identified compounds were calibrated using surrogate standards. Minimum errors of 20 and $50 \%$ were assigned for calibrated and tentatively identified compounds, respectively. The analytical conditions for the pine, straw, and peat smoke samples followed those described by Hatch et al. (2015); analysis of the spruce smoke sample included here was slightly different and is described in the Supplement.
Key advantages of $\mathrm{GC} \times \mathrm{GC}$-TOFMS include improved chromatographic separation and sensitivity compared to 1-D GC, deconvolution capability provided by the high TOFMS spectral collection rate, and the formation of patterns of like compounds in the 2-D retention space that aid in compound classification (Mondello et al., 2008). Therefore, this technique is ideal for speciation of the large number of compounds and isomers emitted from BB (Hatch et al., 2015). However, important polar compounds may adsorb to the glass-fiber filter or may not elute from the GC columns, and light compounds may "break through" the sorbent bed, limiting the range of compounds that can be detected (Hatch et al., 2015). Further, collection of NMOGs onto cartridges yields samples integrated over several minutes or longer, which hinders the ability to capture rapid changes in smoke concentration. However, rapid changes were not expected during the room burn experiments sampled in this work once the smoke was well mixed.

\subsection{Emission factor calculations}

EFs were calculated by the carbon mass balance method (CMB), as described for the OP-FTIR (Stockwell et al., 2014), PTR-TOFMS (Stockwell et al., 2015), and GC $\times$ GCTOFMS (Hatch et al., 2015) measurements. EFs for the WAS measurements of the spruce smoke sample were also calculated by CMB (Eq. 1):

$\mathrm{EF}_{X}=F_{\mathrm{C}} \times \frac{\mathrm{MW}_{X}}{\mathrm{MW}_{\mathrm{C}}} \times \frac{\frac{\Delta X}{\Delta \mathrm{CO}}}{\sum_{i}^{n}\left(\mathrm{CN}_{i} \times \frac{\Delta Y_{i}}{\Delta \mathrm{CO}}\right)}$.

$F_{\mathrm{C}}$ is the mass fraction $\left(\mathrm{gC} \mathrm{kg}^{-1}\right.$ fuel) of carbon in the dry fuel and was measured for each fuel by an independent laboratory. $\mathrm{MW}_{X}$ and $\mathrm{MW}_{\mathrm{C}}$ are the molecular weights (MWs) of compound $X$ and carbon, respectively. $\Delta X$ is the background-subtracted ("excess") mixing ratio of compound $X ; \Delta X / \Delta \mathrm{CO}$ (or $\Delta Y / \Delta \mathrm{CO}$ ) is the emission ratio (ER) of compound $X$ (or $Y$ ) relative to $\mathrm{CO} . \mathrm{CN}_{i}$ is the carbon number in compound $Y_{i}$. The summation represents the total carbon emitted during combustion, assuming complete volatilization. Because the WAS sampling methods are capable of measuring $\mathrm{CO}_{2}, \mathrm{CO}, \mathrm{CH}_{4}$, and light hydrocarbons, all data necessary for $\mathrm{CMB}$ are generally included in the WAS measurements (Simpson et al., 2011). However, due to smoke dilution upon filling the smog chambers, the WAS $\mathrm{CO}_{2}$ and $\mathrm{CH}_{4}$ measurements were below or similar to background levels for the pine, peat, and straw smoke samples. The OPFTIR-measured $\mathrm{CO}_{2}$ and $\mathrm{CH}_{4}$ concentrations could not be substituted directly because of the different dilution ratios between the combustion chamber (OP-FTIR) and smog chamber (WAS), and therefore CMB was not applied to the WAS data set for these three burns. WAS CO measurements were always well above the corresponding background concentrations. Thus for the pine, peat, and straw burns, WAS EFs were calculated via CO-based emission ratios and the OP- 
FTIR CO EF ( $\left.\mathrm{EF}_{\mathrm{CO}}\right)$, as

$\mathrm{EF}_{X}=\frac{\mathrm{MW}_{X}}{\mathrm{MW}_{\mathrm{CO}}} \times \frac{\Delta X}{\Delta \mathrm{CO}} \times \mathrm{EF}_{\mathrm{CO}}$.

\subsection{Data combination and reduction}

Although data and calculated EFs from three of the instruments are available individually (Hatch et al., 2015; Stockwell et al., 2015, 2014), merging into a single, combined $\mathrm{BB}$ emission database will allow a more complete representation of BB emissions and subsequent atmospheric chemistry. To that end, overlapping measurements of the same species must be counted only once to the best possible extent. Data reduction largely followed the approach described by Yokelson et al. (2013). Because of the open-path configuration, the OP-FTIR is not subject to sampling line artifacts. It is also the only instrument that sampled in real time for the duration of each burn (Fig. S1). Therefore all OPFTIR data were given precedence, and EFs determined from the other measurements were discarded for the overlapping compounds due to the greater potential for sampling artifacts. To combine the PTR-TOFMS measurements with speciated data from the GC techniques, the EFs were compared at each chemical formula, summed over all corresponding isomers measured by the GC $\times$ GC-TOFMS and/or WAS instruments. When the PTR-TOFMS EF was more than 2 times the summed GC $\times$ GC-TOFMS or WAS EF, both measurements were retained, unless a negative artifact was known to affect the GC data (e.g., cartridge breakthrough), in which case only the PTR-TOFMS measurement was used in the combined EF database. This approach preserves speciated information while retaining the potential for additional unknown emissions unaccounted for by the GC techniques. It is possible such cases may reflect an incorrect calibration (or sampling artifact) in one or both instruments, and thus compounds may be double-counted in some of these cases. For cases in which the PTR-TOFMS EF was less than 2 times that of the $\mathrm{GC} \times \mathrm{GC}$-TOFMS or WAS EF, the GC data were used to preserve isomer speciation and the PTR-TOFMS measurement was deleted from the synthesized EF database. However, when only one (predominant) isomer was observed in the $\mathrm{GC}$ data set (e.g., $\mathrm{C}_{6} \mathrm{H}_{6}$, benzene), the higher EF was used. For isomer groups detected by both $\mathrm{GC} \times \mathrm{GC}$-TOFMS and WAS, the GC $\times$ GC-TOFMS EFs were retained when many more isomers were observed by this technique; when the number of observed isomers was similar at a given molecular formula, the measurement yielding the higher total EF was used in the EF database. This filtering approach for building a combined database incurs some error, but the errors tend to cancel (Yokelson et al., 2013).

\section{Results and discussion}

\subsection{Historical assessment of BB emission measurements}

In a survey of all publications reporting BB NMOG emissions, species at only a limited number of masses are commonly reported. The compilation (Fig. 1a), which includes 70 publications dating back to the year 2000 (not including review articles), represents the percentage of those publications reporting a quantified NMOG (i.e., concentration, mixing ratio, emission ratio, or emission factor) at the indicated mass. Compounds were lumped by nominal mass; thus multiple compounds can contribute to each molecular weight bin, although each publication is counted only once per bin when more than one isobaric compound was reported. Despite the fact that recent mass spectra of smoke have shown multiple peaks at virtually every mass (Stockwell et al., 2015; Yokelson et al., 2013), only 10 masses are included in over $50 \%$ of the publications; 23 masses are reported over $30 \%$ of the time. The compounds at these 23 commonly reported masses are all of relatively low molecular weight: only four of them are $\geq 100 \mathrm{~g} \mathrm{~mol}^{-1}$.

To demonstrate the volatility range of commonly measured species, we use the compounds compiled in Table 1 of Akagi et al. (2011) as a generous representation of typically reported compounds (online updates to the Akagi et al. (2011) EF database, while not included here, can be found at http://bai.acom.ucar.edu/Data/fire/). The saturation concentration $\left(C^{*}\right)$ of each compound was estimated using the parameterization described by $\mathrm{Li}$ et al. (2016), which is based solely on molecular formulas and thus can be readily applied to both identified and unidentified compounds. In this approach, compounds with the same number of carbon, nitrogen, and oxygen atoms will be assigned the same $C^{*}$ value, regardless of chemical structure or degree of unsaturation. Because halogen atoms are not included in this volatility parameterization, halogenated compounds have been omitted from this assessment. Compounds are plotted in molecular corridors as a function of MW (Li et al., 2016; Shiraiwa et al., 2014) (Fig. 1b). The dashed lines reflect the parameterized change in $C^{*}$ for compounds with $\mathrm{O}: \mathrm{C}=0$ (purple) and $\mathrm{O}: \mathrm{C}=1$ (red) with respect to $\mathrm{MW}$ (Shiraiwa et al., 2014). Regions of $C^{*}$-MW space associated with volatile organic compounds (VOCs), intermediate-volatility compounds (IVOCs), and semi-volatile organic compounds (SVOCs) are shaded for reference (based on the volatility classifications in Donahue et al., 2009). As seen in Fig. 1b, nearly all of the routinely measured species can be classified as VOCs. The five compounds within the IVOC range are organonitrates and are likely misclassified as IVOCs using this parameterization. For example, the parameterized $\log C^{*}$ value of methyl nitrate is 5.05 compared to 8.95 based on the predicted vapor pressure from ChemSpider (http://www. chemspider.com/Chemical-Structure.11231.html). Figure 1 

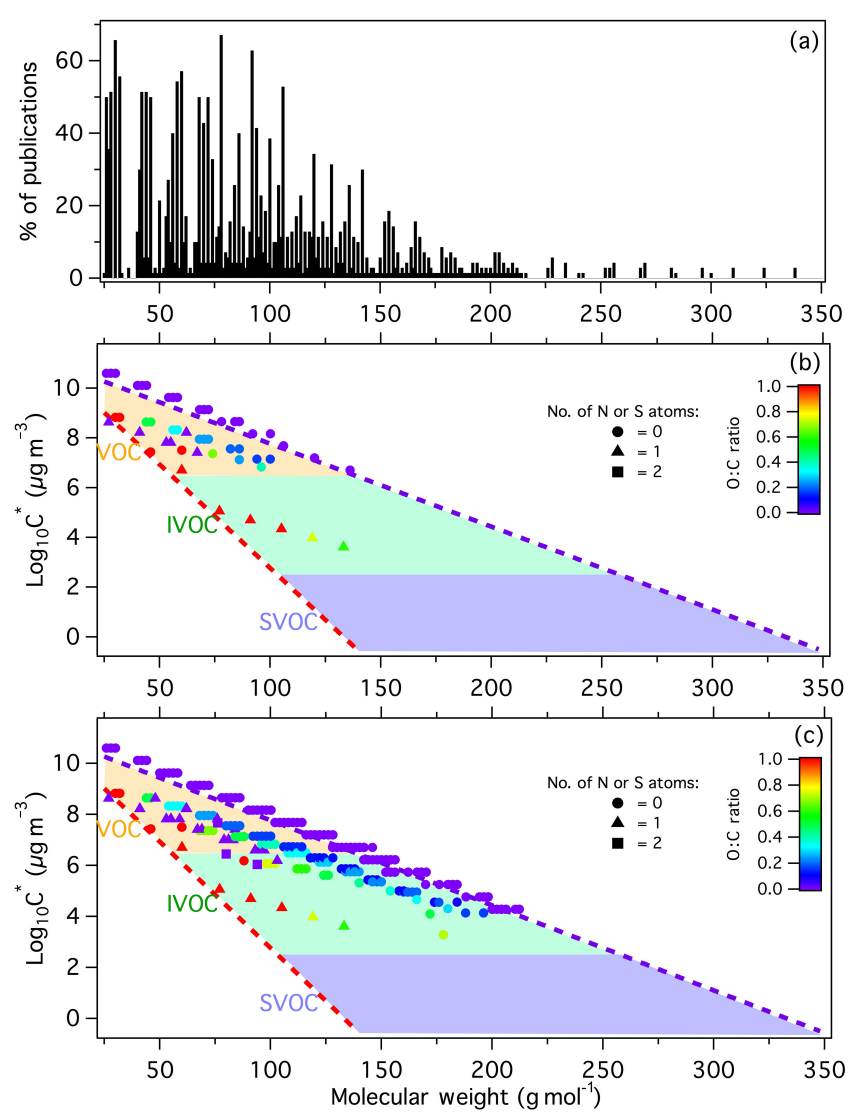

Figure 1. (a) Percent of all relevant publications reporting biomass burning emissions of species at a given molecular weight; (b) molecular corridors representing volatility vs. molecular weight of typically measured NMOGs (Akagi et al., 2011) based on the volatility parameterization of $\mathrm{Li}$ et al. (2016). The approximate ranges for volatile, intermediate-volatility, and semi-volatile compounds (as defined by Donahue et al., 2009) are indicated by the shaded regions; (c) as in panel (b) but for the compounds measured in this work from all fuels. In panels (b) and (c), the color scale saturates at an $\mathrm{O}: \mathrm{C}$ ratio of 1 .

illustrates that traditionally applied measurement approaches miss intermediate to semi-volatile organic compounds, including SOA precursors, which are probed using the combined instrumental analysis described in this work (and plotted in Fig. 1c).

\subsection{Instrument comparison: scope and overlapping species}

\subsubsection{Overall comparison}

Figure 2a shows the range of compounds measured by each instrument, as a function of carbon number $(\mathrm{CN})$ and $\mathrm{H}: \mathrm{C}$ ratio, as well as $\mathrm{O}: \mathrm{C}$ ratio (marker size). Taken together, the instruments yield data for $\mathrm{CO}_{2}, \mathrm{CO}, \mathrm{CH}_{4}$, and NMOGs from $\mathrm{C}_{1}$ to $\mathrm{C}_{15}$, including compounds with a wide range of doublebond equivalents (DBE, $0-7)$ and $\mathrm{O}: \mathrm{C}$ ratios $(0-3$; methyl
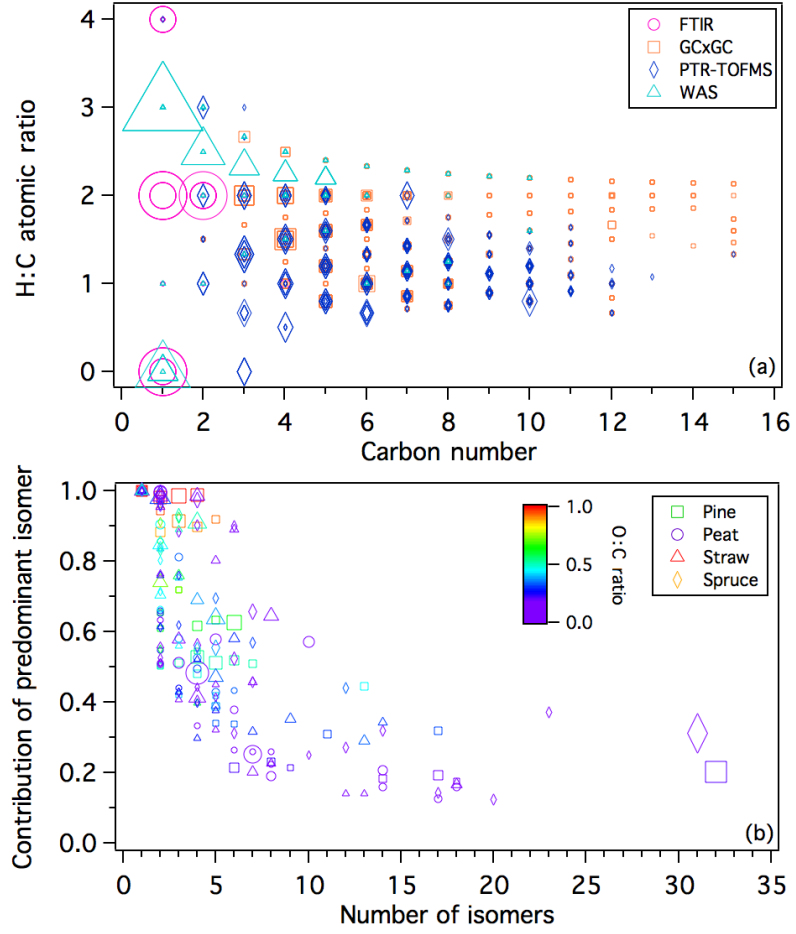

Figure 2. (a) Comparison of the range of compounds measured by each instrument as a function of $\mathrm{H}: \mathrm{C}$ ratio and carbon number. Marker size is proportional to the $\mathrm{O}: \mathrm{C}$ ratio. Data from all four burns are represented; (b) contribution of the predominant isomer as a function of the number of observed isomers. Marker size is proportional to the contribution of each isomer group to the total NMOG EF (from 0 to $5 \%$ ).

nitrate contributes the highest $\mathrm{O}: \mathrm{C}$ ratio) (Fig. 2a). Further, each instrument detected unique compounds and/or covered unique regions in $\mathrm{CN}-\mathrm{H}$ : $\mathrm{C}$ space. The WAS technique measured organonitrates (large triangles in Fig. 2a), as well as light HCs, particularly alkanes $\leq \mathrm{C}_{4}$. GC $\times$ GC-TOFMS measured the highest MW HCs, including alkanes, alkenes, and sesquiterpenes, whereas the PTR-TOFMS measured more polar compounds. In this study, the OP-FTIR contributed the data needed for CMB EF calculations for the PTR-TOFMS and $\mathrm{GC} \times \mathrm{GC}$-TOFMS (i.e., $\mathrm{CO}, \mathrm{CO}_{2}$, and $\mathrm{CH}_{4}$ ), as well as light oxygenates, such as formic and acetic acids, glycolaldehyde, and formaldehyde.

The coverage of each instrument as a function of compound volatility is also shown in Table 1, where the values represent the percentage of the total EF measured by a given instrument relative to the total EF determined from the combined data set following data synthesis. For this representation, percentages include EFs for overlapping species as detected by each instrument, even if they were eliminated from the combined database during data reduction. Values in parentheses include EFs determined by OP-FTIR for overlapping compounds that the indicated instrument is capable of measuring but that were not quantified in this study 
Table 1. Total EF (in $\mathrm{g} \mathrm{kg}^{-1}$ fuel burned) and the percentage of the total EF measured by each instrument for different classes of compounds.

\begin{tabular}{llrrr}
\hline Fuel & Instrument & All compounds & NMOG & IVOC \\
\hline Ponderosa pine & Total EF $\left(\mathrm{g} \mathrm{kg}^{-1}\right)$ & 1780 & 36.5 & 3.96 \\
& OP-FTIR $(\%)$ & 99 & 36 & 0.0 \\
& WAS $(\%)$ & $5.2(98)$ & 26 & 0.2 \\
& GC $\times$ GC-TOFMS $(\%)$ & 0.7 & 31 & 17 \\
& PTR-TOFMS $(\%)$ & $1.1(1.6)$ & $55(79)$ & 88 \\
Black spruce & Total EF & 1820 & 37.3 & 2.31 \\
& OP-FTIR & 99 & 28 & 0.0 \\
& WAS & 99 & 18.0 & 0.3 \\
& GC $\times$ GC-TOFMS & 0.48 & 23 & 27 \\
& PTR-TOFMS & $1.2(1.6)$ & $59(76)$ & 79 \\
Indonesian peat & Total EF & 2030 & 53.1 & 4.00 \\
& OP-FTIR & 98 & 21 & 0.0 \\
& WAS & $13(99)$ & 58 & 0.9 \\
& GC $\times$ GC-TOFMS & 0.7 & 28 & 45 \\
& PTR-TOFMS & $0.7(1.3)$ & $29(50)$ & 59 \\
Chinese rice straw & Total EF & 1500 & 9.53 & 0.67 \\
& OP-FTIR & 99 & 32 & 0.0 \\
& WAS & $4.0(99)$ & 30 & 0.1 \\
& GC $\times$ GC-TOFMS & 0.2 & 35 & 37 \\
& PTR-TOFMS & $0.3(0.4)$ & $47(68)$ & 84 \\
\hline
\end{tabular}

(i.e., overlapping compounds between PTR-TOFMS and OPFTIR (Stockwell et al., 2015) and $\mathrm{CO}_{2}+\mathrm{CH}_{4}$ in the WAS data for reasons discussed in Sect. 2.2). "All compounds" represent the sum of NMOGs, $\mathrm{CO}, \mathrm{CO}_{2}$, and $\mathrm{CH}_{4}$. The allcompounds category is dominated by $\mathrm{CO}, \mathrm{CO}_{2}$, and $\mathrm{CH}_{4}$ (see also Figs. 4 and 5), which typically constitute $>97 \%$ of the total carbon emitted by BB (Akagi et al., 2011; Yokelson et al., 2013; Gilman et al., 2015). The OP-FTIR and WAS samples (with $\mathrm{CO}_{2}$ and $\mathrm{CH}_{4}$ included) detected $~ 98-99 \%$ of the total gas-phase EF. For the NMOG and IVOC categories, PTR-TOFMS generally measured the highest fraction of the total EF regardless of whether the OP-FTIR overlapping species were included or not (Table 1). The peat burn was the only case for which the GC measurements accounted for a similar fraction of the total NMOG EF, due to the higher contribution of alkanes than for the other smoke samples (32\% of the total NMOG EF compared to $<6 \%$ for the other fuels). Because PTR-MS instruments using $\mathrm{H}_{3} \mathrm{O}^{+}$reagent ions are not sensitive to alkanes (Arnold et al., 1998), this major class of compounds would be entirely unaccounted for if only PTR-MS measurements were used to measure peat smoke.

In addition to mass closure, speciation of the observed compounds is required for understanding chemical reaction pathways. Figure $2 b$ shows the number of isomers and the contribution of the top isomer to the total EF at that molecular formula, as determined by the chromatographic methods for each molecular formula that overlapped with PTRTOFMS. Note that there are some polar compounds for which $\mathrm{GC} \times \mathrm{GC}$-TOFMS likely missed a dominant isomer (e.g., catechol at $\mathrm{C}_{6} \mathrm{H}_{6} \mathrm{O}_{2}$ ), which would bias this analysis for a few compounds. To illustrate the relative abundance of each isomer group, the marker sizes in Fig. 2 b are proportional to the percent contribution of each group (based on the GC EFs) to the total NMOG EF from Table 1.

For $33 \%$ (peat) $-46 \%$ (pine) of the $56-60 \mathrm{~m} / \mathrm{z}$ ratios per fuel included in the comparison, $4+$ (and up to 32) isomers could be observed chromatographically. In contrast, only $22 \%$ (straw) $-38 \%$ (peat) of all included $\mathrm{m} / \mathrm{z}$ ratios corresponded to a single isomer in the GC data sets, although some of the most abundant isomer groups can be reasonably treated as a single isomer despite the presence of multiple minor isomers (top left corner of Fig. 2b; e.g., benzene and toluene). However, many relatively abundant isomer groups were not dominated by a single isomer. Particularly in the 4-10 isomer range, many isomer groups that represent a significant portion of the NMOG EF were observed wherein the top isomer contributed only $\sim 25-75 \%$ of the EF for that group (Fig. 2b). For groups with $10+$ observed isomers, which were overwhelmingly hydrocarbons, the range decreased to only $\sim 15-60 \%$ (Fig. 2b), although such groups represent a relatively small percentage of the NMOG EF, with the notable exception of the monoterpenes (Fig. 2b). In spruce and pine smoke, monoterpenes made the largest contribution to the total EF (4.8 and 3.1\%, respectively, based on the GC $\times$ GC-TOFMS EFs) and had the highest number of isomers ( $>30)$ among the compounds included in Fig. 2b, with the top isomer contributing $<30 \%$ of the total monoterpene EF. Therefore, a number of important isomers were detected chromatographically for many of the overlap- 
ping $m / z$ ratios observed by PTR-TOFMS, highlighting the difficulty in determining specific compounds using chemical ionization. Future studies that include a larger number of sampled fires could probe the variability of the isomer distribution within each isomer group to determine the conditions/fuels for which scaling factors could be reasonably applied in order to coarsely speciate PTR-TOFMS data.

\subsubsection{Instrument vs. instrument}

Figure 3a shows the correlation between the EFs calculated based on the GCs and OP-FTIR/PTR-TOFMS data; statistics of the comparison for each instrument pair are provided in Table 2. Each PTR-TOFMS EF is compared to the sum of EFs of all isomers at the same molecular formula, as measured by the respective GC instruments. Including overlapping compounds among all four instruments, 65-72 unique molecular formulas are included in the comparison for each fuel, making this the most comprehensive comparison of $\mathrm{BB}$ emissions to date and the first to include data from these specific analytical approaches.

Significant overlap with the OP-FTIR measurements is only available for the WAS data set (Table 2). These two techniques are the most established and well characterized of the four, and they displayed the best correlation among all instrument pairs (slope $=1.01 \pm 0.001, r^{2}=1.0$, Table 2), despite measuring smoke at different dilution ratios. Only furan overlaps between the GC $\times$ GC-TOFMS and OP-FTIR; thus the correlation between these instruments was not assessed. Because PTR-TOFMS-derived EFs were not calculated for the few compounds that overlap with the OP-FTIR (Stockwell et al., 2015), comparison of these two instruments is not available; however Stockwell et al. (2015) previously reported a strong correlation between the OP-FTIR and PTRTOFMS methanol data during the FLAME-4 stack burns.

The correlation between the GC $\times$ GC-TOFMS and WAS data is given in Fig. S2 and demonstrates good agreement between these two methods for overlapping isomers (slope $=1.32 \pm 0.08, r^{2}=0.82$, Table 2). All data points with the largest discrepancy occurred during the peat burn (Fig. S2). When the peat smoke data points are removed from the linear regression, the slope and $R^{2}$ improve to 1.11 and 0.95 , respectively, indicating that these techniques generally agreed within $\sim 10 \%$ among the overlapping isomers (i.e., within the reported uncertainty for the $\mathrm{GC} \times \mathrm{GC}$ TOFMS data). The reason for the larger discrepancy in the peat smoke measurements is not entirely clear. Given the multi-column and multi-detector analysis of the canister samples (see Sect. 2.1.2), the likelihood of interferences in the WAS detection is significantly reduced. However, because the peat burn produced the lowest smoke concentrations, WAS-measured excess mixing ratios were significantly lower than for the other burns and thus potentially subject to greater uncertainty given the additional dilution upon filling the smog chambers. Further, because the WAS canister sam-
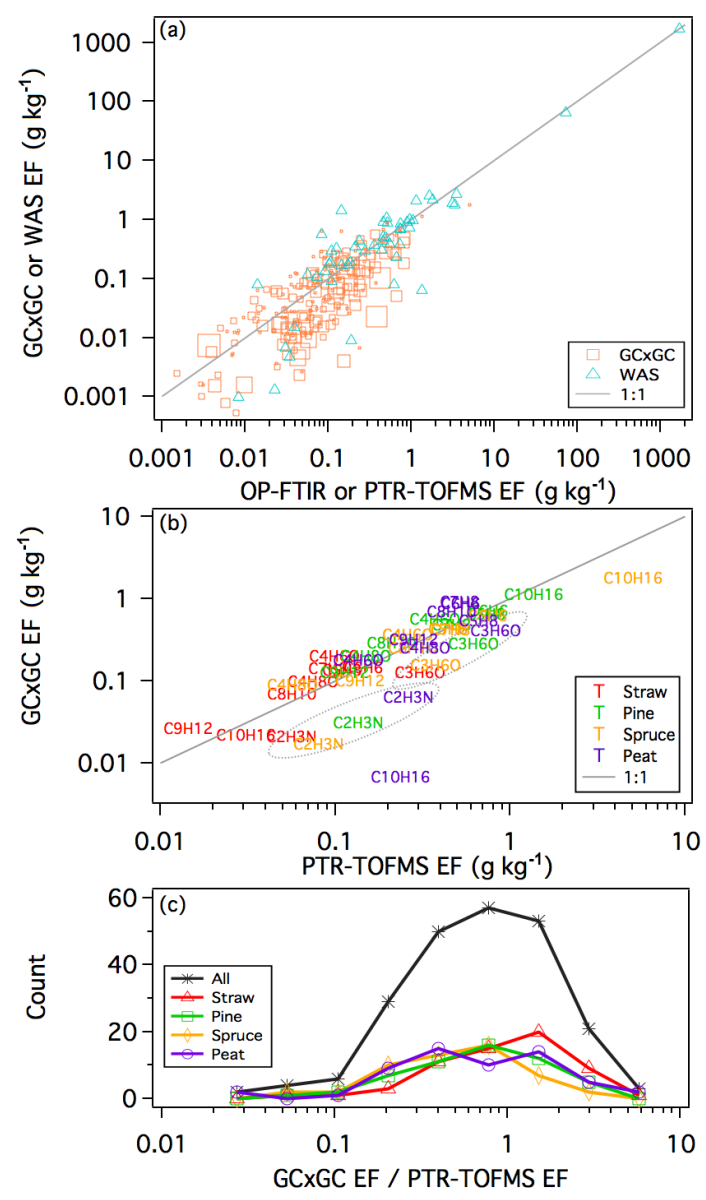

Figure 3. (a) Comparison of the emission factors determined by GC $\times$ GC-TOFMS or WAS ( $y$ axis) with those measured by PTRTOFMS or OP-FTIR. Marker size is proportional to $\mathrm{O}: \mathrm{C}$ ratio for $\mathrm{GC} \times \mathrm{GC}$-TOFMS comparisons only; (b) comparison of $\mathrm{GC} \times \mathrm{GC}$ TOFMS and PTR-TOFMS emission factors determined for overlapping standard (i.e., calibrated) compounds only. Dotted gray circles denote compounds affected by known breakthrough artifacts during cartridge sampling; (c) histogram of the ratio of GC $\times$ GC-TOFMS emission factors relative to PTR-TOFMS emission factors for all overlapping compounds within individual burns and summed over all burns.

ples were collected from the smog chambers, rather than directly from the combustion chamber, we cannot rule out the potential that the analyte concentrations were different than those measured by $\mathrm{GC} \times \mathrm{GC}-\mathrm{TOFMS}$ during the peat burn (after accounting for dilution; e.g., due to contamination during the chamber fill), although the other burns did not appear to be impacted based on the good agreement between the two methods (Fig. S2). It is also possible that poor isomer separation, poor mass spectral deconvolution, or incorrect isomer assignments impacted the GC $\times$ GC-TOFMS calibration. Future experiments should compare these techniques side by side. 
Table 2. Linear regression statistics for each instrument pair. For all linear regressions, the $y$ intercept was forced through zero.

\begin{tabular}{lrrr}
\hline Instrument pair & $\begin{array}{c}\text { No. of overlapping } \\
\text { molecular formulas }\end{array}$ & Slope & $R^{2}$ \\
\hline WAS, OP-FTIR & 6 & $1.01 \pm 0.001$ & 1.0 \\
WAS, PTR-TOFMS & 12 & $0.9 \pm 0.1$ & 0.50 \\
WAS, GC $\times$ GC-TOFMS & 14 & $1.32 \pm 0.08$ & 0.82 \\
GC $\times$ GC-TOFMS, PTR-TOFMS & 72 & $0.48 \pm 0.02$ & 0.83 \\
GC $\times$ GC-TOFMS, OP-FTIR & 1 & - & - \\
\hline
\end{tabular}

The 12 overlapping compounds between WAS and PTRTOFMS included hydrocarbons and dimethyl sulfide. The relatively low $R^{2}$ value $(0.50)$ can be partly attributed to cases where the WAS measured only a portion of the possible isomers at a given molecular formula (e.g., isoprene and monoterpenes), although the slope (WAS vs. PTR, $0.9 \pm 0.1$ ) indicated reasonable overall agreement (Table 2). The WAS DMS EF, however, is 7-17 times lower than that determined by PTR-TOFMS, despite being directly calibrated in both data sets. A recent study comparing the detection of organosulfur compounds between these two techniques demonstrated good agreement for DMS (Perraud et al., 2016); thus the reason for this discrepancy in this work is currently unknown.

The most overlapping compounds (72) were observed between GC $\times$ GC-TOFMS and PTR-TOFMS (Table 2). The compounds that were directly calibrated in both instruments are compared in Fig. $3 b$ and include light oxygenates, aromatic compounds, and isoprene/monoterpenes. Acetone $\left(\mathrm{C}_{3} \mathrm{H}_{6} \mathrm{O}\right)$ and acetonitrile $\left(\mathrm{C}_{2} \mathrm{H}_{3} \mathrm{~N}\right)$ are known to break through the ATD cartridges used for $\mathrm{GC} \times \mathrm{GC}$-TOFMS sample collection (Hatch et al., 2015) and thus are expectedly below the 1:1 line (outlined with gray circles, Fig. 3b). Despite the underestimation by the GC $\times$ GC-TOFMS, the EFs for acetone and acetonitrile are linearly correlated with those determined by PTR-TOFMS (Fig. 3b). Other calibrated compounds (except monoterpenes) agree well between the two instruments, falling close to the $1: 1$ line (slope $=1.08 \pm 0.06, R^{2}=0.96$ not including acetone, acetonitrile, and monoterpene data points), despite application of single isomers for PTR-TOFMS calibration (Sect. 2.1.3).

In contrast to the other standard compounds, the monoterpene (MT, $\left.\mathrm{C}_{10} \mathrm{H}_{16}\right)$ EFs exhibited greater variability between the two instruments. In addition to the parent ion occurring at $m / z 137\left(\mathrm{C}_{10} \mathrm{H}_{17}^{+}\right)$, MTs are known to fragment following protonation in PTR-MS instruments, yielding a major fragment ion at $m / z 81\left(\mathrm{C}_{6} \mathrm{H}_{9}^{+}\right)$; the degree of fragmentation is isomer dependent (Maleknia et al., 2007; Tani et al., 2003; Warneke et al., 2003). The MT emission factors reported by Stockwell et al. (2015) were calibrated using $m / z 81$ due to the high degree of fragmentation of the $\alpha$-pinene standard under the PTR-TOFMS drift tube conditions utilized during FLAME-4. A comparison of the calculated MT EFs deter- mined using $m / z 137\left(\mathrm{EF}_{137}\right)$ and $m / z 81\left(\mathrm{EF}_{81}\right)$ is given in Fig. S3 and shows that $\mathrm{EF}_{137}$ varies between $\sim 15$ and $95 \%$ of $\mathrm{EF}_{81}$. The widest differences between $\mathrm{EF}_{137}$ and $\mathrm{EF}_{81}$ occurred in the fires of fuels that are not known to be MT emitters (i.e., rice straw, Kesselmeier and Staudt, 1999; peat, Fig. S3). The high $\mathrm{EF}_{81}$ values for such smoke samples can be partly attributed to the presence of $\mathrm{C}_{6} \mathrm{H}_{8}$ compounds in BB smoke, which will be detected at $m / z 81$ upon protonation. Based on the $\mathrm{GC} \times \mathrm{GC}-\mathrm{TOFMS}$ data, $\mathrm{EF}\left(\mathrm{C}_{6} \mathrm{H}_{8}\right)$ is 1.5 and 16 times that of $\mathrm{EF}\left(\mathrm{C}_{10} \mathrm{H}_{16}\right)$ in straw and peat smoke, respectively, indicating that $\mathrm{C}_{6} \mathrm{H}_{8}$ compounds can significantly interfere with the determination of MT EFs based on PTR-MS data calibrated using $m / z$ 81. Based on this assessment, we find that PTR-TOFMS EFs calculated using $m / z, 137$ displayed better agreement with the GC $\times \mathrm{GC}$ TOFMS-calculated MT EFs (summed over all isomers). The mean difference between the PTR-TOFMS and GC $\times$ GCTOFMS MT EFs improved from 1.2 to $0.93 \mathrm{~g} \mathrm{~kg}^{-1}$ when $\mathrm{m} / z 137$ was used for calibration instead of $m / z 81$; when the spruce smoke data points due to other potential interference were omitted (discussed below), the mean difference among the remaining three MT samples improved from 0.51 to $0.15 \mathrm{~g} \mathrm{~kg}^{-1}$.

Despite the improved agreement using $\mathrm{EF}_{137}$, the PTRTOFMS MT EF remains 2.8 times (spruce) and 35 times (peat) higher than that measured by GC $\times$ GC-TOFMS, compared with 1.2 and 1.4 times for pine and straw, respectively (Fig. 3b). Interference from other species at $m / z 137$ is possible and would likely vary from fuel to fuel. For example, the presence of bornyl acetate $\left(\mathrm{C}_{12} \mathrm{H}_{20} \mathrm{O}_{2}\right)$ may explain the nearly threefold higher MT EF in spruce smoke. Bornyl acetate has been found to compose nearly $50 \%$ of the essential oil in black spruce needles (more than all MTs combined) (von Rudloff, 1975) and is further detected at the MT masses in PTR-MS measurements $(\mathrm{m} / z 137$ and 81) due to fragmentation and loss of $\mathrm{C}_{2} \mathrm{H}_{4} \mathrm{O}_{2}$ (Kim et al., 2010). In addition to a small bornyl acetate EF calculated from the GC $\times$ GC-TOFMS cartridge measurements of the spruce fire (Table $\mathrm{S} 1$ ), the qualitative $\mathrm{GC} \times \mathrm{GC}$-TOFMS analysis of species desorbed from filter samples (see Hatch et al., 2015 , for details) showed that the bornyl acetate peak area was $\sim 6$ times higher than the second-most-abundant compound observed in the spruce smoke filter samples (data not 
shown), indicating that significant concentrations of bornyl acetate were indeed present in spruce smoke. Thus bornyl acetate may have contributed significantly to the PTR-TOFMS MT signal in the spruce burn and the discrepancy with the GC $\times$ GC-TOFMS MT measurement; however the extent of such interference is currently unknown.

The large MT discrepancy in peat smoke is more puzzling, particularly because it is not known how much MT emissions are expected from burning peat that is derived mostly from plant matter that has decayed over hundreds of years. The peat burned here was a core sample taken from a disturbed site and likely included some non-peat fuels that may influence the potential MT emissions. A duplicate cartridge sample of the peat burn analyzed on a second column set (see Supplement; data not shown) confirmed that negligible MT emissions were observed by GC $\times$ GC-TOFMS during this burn. However, an EF of $0.43 \mathrm{~g} \mathrm{~kg}^{-1}$ for $\alpha$-pinene $+\beta$ pinene was calculated in the peat burn from the WAS measurements, which is nearly twice as high as the PTR-TOFMS MT EF of $0.24 \mathrm{~g} \mathrm{~kg}^{-1}$. We note that the WAS EF for $\alpha$ pinene $+\beta$-pinene was zero for spruce smoke, where abundant MT emissions would be expected from the burning of fresh ( $<1$ week old) boughs. A GC $\times$ GC-TOFMS measurement from the peat smog chamber experiment showed negligible MT levels, so smog chamber contamination does not appear to have played a role in the WAS measurement. Although unknown problems in the cartridge sampling and/or analysis cannot be completely ruled out at this time, it is unlikely that MTs present in peat smoke would have gone undetected in three different cartridge samples (two room burn replicates + one smog chamber sample) during $\mathrm{GC} \times \mathrm{GC}$ TOFMS analysis. Given the wide variability among these instruments for the determination of MTs and the extent to which these or similar techniques are used to measure ambient MTs, more work is clearly needed to understand the emissions of these compounds.

Regarding potential MT interference during PTR-MS analysis, we additionally highlight that oxygenated compounds with nominal MW of $136 \mathrm{~g} \mathrm{~mol}^{-1}$ were observed by PTR-TOFMS during FLAME-4 (Stockwell et al., 2015). For peat and straw smoke, the combined EF of such compounds were $\sim 30$ and $\sim 44 \%$ that of the MT EF, respectively, compared to $\sim 11 \%$ (pine) and $\sim 1 \%$ (spruce) for the conifers. Thus MT EFs determined using PTR-MS instruments equipped with unit mass resolution mass analyzers (e.g., quadrupole) could be considerably overestimated for burns of fuels that are not MT emitters. Therefore, caution is warranted for the determination of MT EFs in smoke using PTR-MS instruments due the high complexity of BB emissions.

The correlation of all overlapping data between $\mathrm{GC} \times \mathrm{GC}$ TOFMS and PTR-TOFMS is given in Fig. 3a, where essentially all $\mathrm{GC} \times \mathrm{GC}$-TOFMS data points are associated with PTR-TOFMS measurements due to the very limited overlap with OP-FTIR. The agreement $\left(\right.$ slope $=0.48 \pm 0.02, R^{2}=$
0.83, Table 2) among all overlapping compounds is not as robust as for the calibrated compounds. To more clearly show the range of the comparison, a histogram of the ratio of GC $\times$ GC-TOFMS EFs to PTR-TOFMS EFs is included in Fig. $3 \mathrm{c}$ for individual burns, as well as cumulatively for all four burns. The distribution is nearly log-normal, with a longer tail at low ratios. The geometric mean among all burns is 0.65 (geometric standard deviation $=0.42$, median $=0.71$ ); a similar distribution is observed for all fuels. The mean and median lie closer to 1 than the slope of the correlation plot because the distribution statistics are less influenced by outliers, particularly those at high EFs. In particular, the slope of the correlation plot is significantly influenced by the high spruce MT EF determined by PTRTOFMS (described above; Fig. 3b); when that data point was removed from the linear regression as a sensitivity test, the slope improved to $0.75 \pm 0.03$, in closer agreement with the histogram mean and median. This demonstrates that the GC $\times$ GC-TOFMS and PTR-TOFMS generally agreed within $\sim 30 \%$ on average, which is within the reported uncertainties for each measurement.

The poorer agreement between the $\mathrm{GC} \times \mathrm{GC}$-TOFMS and PTR-TOFMS compared with the other instrument pairs (Table 2) can be due to multiple factors, including that quantification of uncalibrated compounds is subject to significant error. Such compounds were calibrated using surrogate standards (GC $\times$ GC-TOFMS; Hatch et al., 2015) or massdependent calibration factors (PTR-TOFMS; Stockwell et al., 2015). Therefore, the overall agreement could be improved by more thoroughly calibrating the PTR-TOFMS data and directly calibrating the overlapping species detected by $\mathrm{GC} \times \mathrm{GC}-\mathrm{TOFMS}$, as indicated by the close agreement among the standard compounds (Fig. 3b). Further, polar compounds are more likely to be underestimated by GC $\times$ GC-TOFMS where significant isomers may not elute from the GC columns or may be lost to the glass-fiber filter used during sampling. This underestimation can be seen in Fig. 3a, where markers for $\mathrm{GC} \times \mathrm{GC}$-TOFMS data points are scaled by $\mathrm{O}: \mathrm{C}$ ratio (from 0 to 0.75 for $\mathrm{GC} \times \mathrm{GC}$-TOFMS data; none of the WAS NMOGs that overlap with other instruments are oxygenated, and thus for visual clarity these markers were not scaled). Many of the compounds with relatively high $\mathrm{O}: \mathrm{C}$ ratios fall below the $1: 1$ line, highlighting the general underestimation of oxygenated compounds by $\mathrm{GC} \times \mathrm{GC}-\mathrm{TOFMS}$. Thus, more work is needed to understand and optimize the GC $\times$ GC-TOFMS sampling and analysis methods to characterize polar compounds in BB emissions.

\subsection{Emission characterization}

Discrepancies among the instruments were generally well understood and provided sufficient confidence in the data to construct emission profiles. Figures 4 and 5 show the overall gas-phase composition including all measurements 

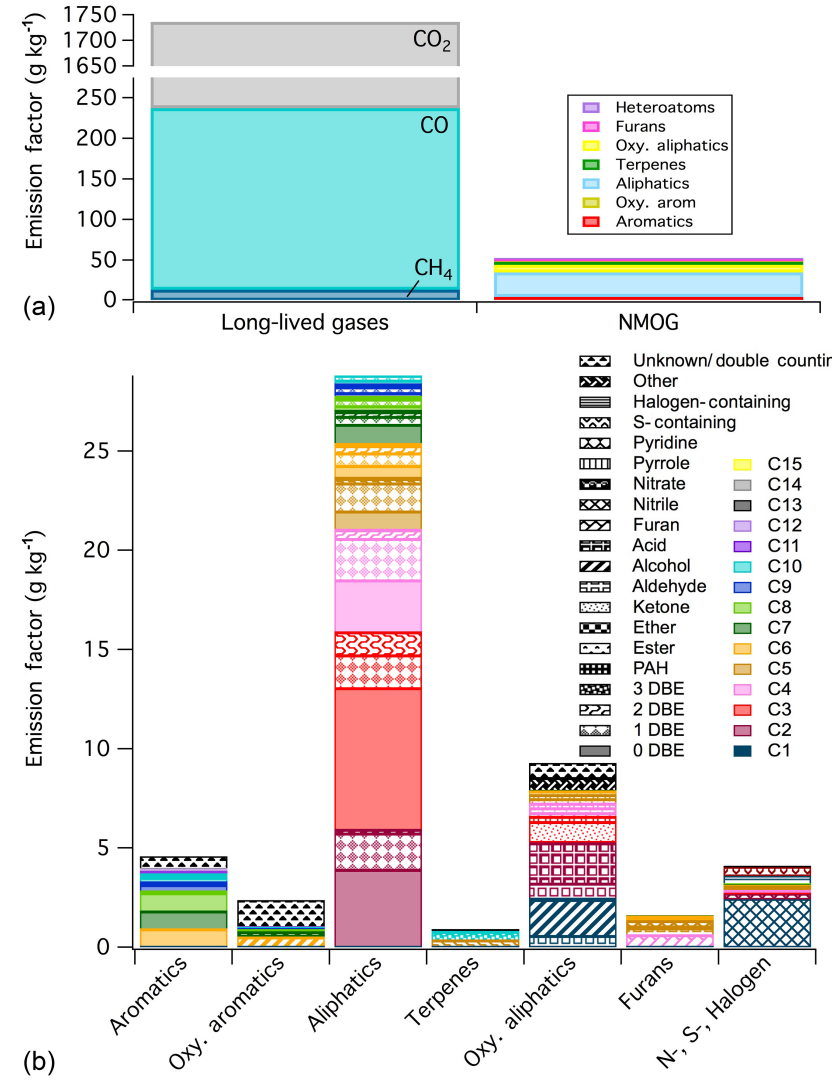

Figure 4. Gas-phase emission factors from an Indonesian peat fire. Top panel: long-lived gases compared to NMOG. Bottom panel: speciation of NMOG; colors represent carbon number, and patterns indicate functionality. "DBE" - double-bond equivalents.

for peat and straw smoke, respectively, sorted into major chemical classes; analogous figures for pine and spruce smoke are shown in Figs. S4 and S5. The synthesized EF database is included in Table S1. Although furans are aromatic compounds, they are treated as a separate class; "aromatic" in this paper therefore refers to benzene derivatives. Unknown compounds in the PTR-TOFMS data set were categorized based on the number of double-bond equivalents (i.e., compounds with $\mathrm{DBE} \geq 4$ were assigned as aromatic); such compounds, particularly oxygenates, are included in the "unknown/double-counting category", due to the lack of information regarding functional groups. This category includes compounds for which both PTR-TOFMS and GC $\times$ GC-TOFMS or WAS data were kept (Sect. 2.3). These cases reflect either an incorrect calibration or sampling artifact in one or both instruments (leading to double counting) or unknown compounds unaccounted for by the GC techniques. Therefore, the unknown/double-counting segments are most likely to be revised or reclassified by future measurements. The total number of compounds observed per fuel following data reduction ranged from 467 (peat) to 569 (pine), including isomers and a few potentially

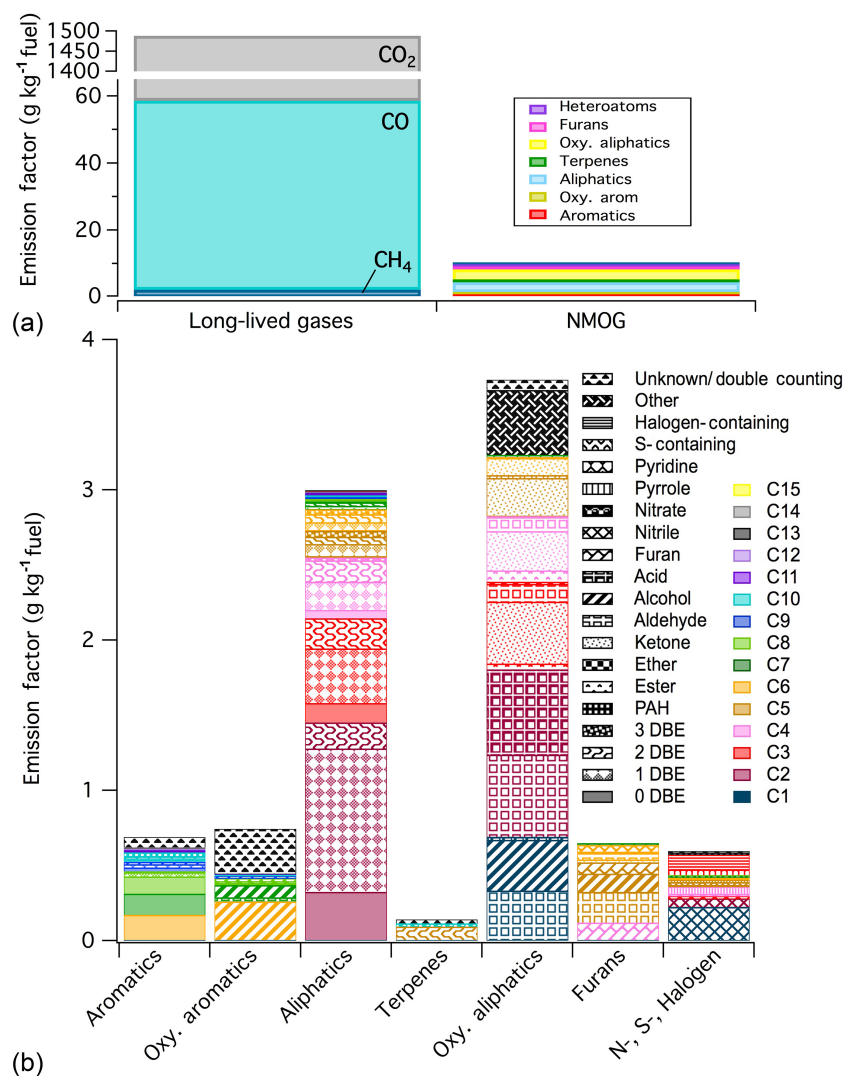

Figure 5. As in Fig. 4 but for a Chinese rice straw fire.

double-counted compounds (Table S1). For comparison, the number of unique chemical formulas ranged from 164 (peat) to 180 (straw), demonstrating not only the diversity of compounds emitted from BB but also the large number of isomers detected by the GC techniques (Fig. 2b).

NMOG profiles for straw (Fig. 5), pine (Fig. S4), and spruce (Fig. S5) are similar, with the largest contribution being from oxygenated aliphatic compounds, followed by aliphatic HCs. Recently Gilman et al. (2015) determined that oxygenated NMOGs constituted $57-68 \%$ of all BB emissions compiled from GC-MS, OP-FTIR, and a variety of chemical ionization mass spectrometer measurements from laboratory burns of fuels common to different regions of the United States. In this work, the percentage of all oxygenated NMOGs for pine and straw smoke was similar at 55 and $54 \%$ of the NMOG EF, respectively. The oxygenates in spruce smoke composed only $43 \%$ of the total NMOG EF, partly due to the very high MT emissions measured by PTRTOFMS (Fig. S5 and Sect. 3.2.2). Further, oxygenates constituted only $25 \%$ of the emissions in peat smoke, which was dominated by aliphatic HCs (57\%, Fig. 4). In all smoke samples, compounds with $\mathrm{CN} \leq 3$ constitute $40-50 \%$ of the total NMOG EF, largely due to ethene, methanol, formaldehyde, acetaldehyde, and acetic acid (Figs. 4-5, S4-S5). 


\subsubsection{Volatility}

The $C^{*}$ of all measured NMOGs was estimated using the parameterization of Li et al. (2016) described in Sect. 3.1. The compounds are displayed in molecular corridors in Fig. 1c and highlight that a large number of $\mathrm{HC}$ and oxygenated IVOCs were detected (IVOCs defined as $\log C^{*}=$ 3-6 $\mu \mathrm{g} \mathrm{m}^{-3}$; Donahue et al., 2009). Approximately 65 unique molecular formulas (range 61-68 across fuels) were measured in the IVOC range. Except for organonitrates, which are likely misclassified as IVOCs using this approach, all IVOCs determined in FLAME-4 were measured solely by PTR-TOFMS and GC $\times$ GC-TOFMS. In all cases, the PTRTOFMS measured a higher fraction of IVOCs than GC $\times$ GCTOFMS (Table 1), likely due in part to the use of a heated sample inlet with the PTR-TOFMS measurements, which provides improved transmission of lower-volatility compounds compared to the room temperature sample line and filter used for cartridge sampling (Sect. 2.1.3 and 2.1.4). Based on the applied $C^{*}$ parameterization and volatility classifications, no SVOCs were detected with the analytical methods applied in this work (Fig. 1c). It is expected that with the high OA concentrations, $\sim 1000-6000 \mu \mathrm{g} \mathrm{m}^{-3}$ (based on OC-EC (elemental carbon) analysis of FLAME4 filter samples; protocol described by Jayarathne et al., 2014), much of the SVOC was likely present in the condensed phase. Additionally, SVOCs may have been lost to surfaces present in the combustion chamber (e.g., as has been modeled by Bian et al. (2015) for smog chambers). As seen in Fig. 1a, there are a few publications for which SVOCs in gaseous BB emissions (e.g., MW $>\sim 250$ for HCs) have been reported (Garcia-Hurtado et al., 2014; Hays et al., 2002; Schauer et al., 2001). However, more work is needed to better identify and quantify the semi-volatile components of BB smoke.

To further probe the fraction of the NMOG EF attributable to IVOCs, all NMOGs were binned by estimated $C^{*}$. The resulting EF distribution as a function of volatility is included in Fig. 6 for pine smoke; analogous figures for the other fuels are included in the Supplement (Figs. S6-S8). The volatility of compounds measured across all four instruments during FLAME-4 spans 9 orders of magnitude; seven of these bins contain significant mass. In the pine smoke sample, IVOCs accounted for $\sim 11 \%$ of the total NMOG EF (6-8\% for the other fuels; Table 1), the majority of which falls at the high end of the IVOC volatility range (i.e., $\log C^{*} \sim 5-6$; Figs. 6, S6-S8). As with the SVOCs, the lowest-volatility IVOCs $\left(\log C^{*}=3-4 \mu \mathrm{g} \mathrm{m}^{-3}\right)$ likely exist to some extent in the particle phase given the high OA mass concentrations; calculated EFs for those compounds therefore would be higher under lower OA mass loadings. For comparison, the compounds typically measured in BB smoke (based on Table 1 of Akagi et al., 2011) and those included in the EPA SPECIATE emission inventory (EPA, 2008) are also included. Because the EFs (or compound weighting) of these two com-

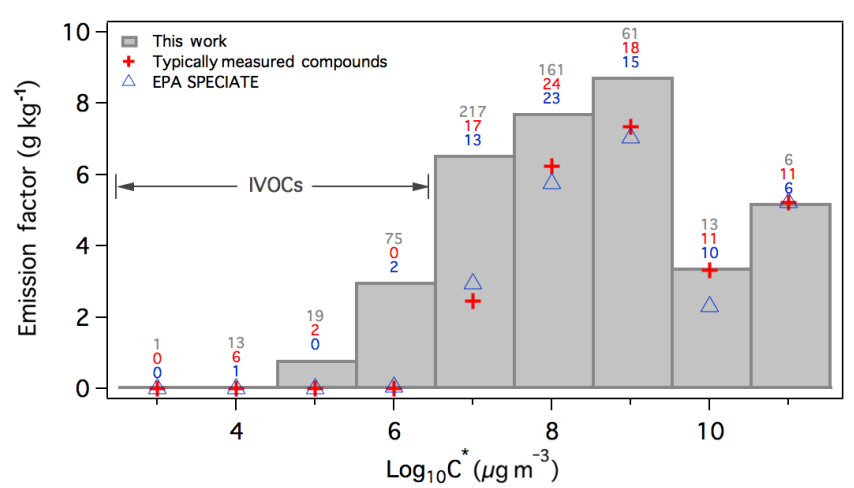

Figure 6. Emission factors of NMOG determined in pine smoke, as a function of volatility (see text). Red $(+)$ and blue $(\Delta)$ markers indicate the contribution from typically measured compounds based on Akagi et al. (2011) and the EPA SPECIATE emission inventory (EPA, 2008), respectively. The number of compounds included in each bin is indicated above the bars.

pilations are based on an ecosystem average (e.g., temperate forest) whereas the FLAME-4 data are based on a single burn of a single fuel, comparison of EF values among these studies is not very meaningful. Rather, we emphasize the portion of FLAME-4 emissions that would have been observed if only the routine compounds had been measured; thus for each compound included in Akagi et al. (2011) or the SPECIATE inventory we have applied the corresponding EF from the combined FLAME-4 data set (Table S1).

The volatility of the compounds in both Akagi et al. (2011) and SPECIATE spans 8 orders of magnitude; however compounds in only five bins contribute significantly to the overall EF in both cases (Fig. 6). The compounds included in the SPECIATE database and Akagi et al. (2011) account for 63 and $66 \%$, respectively, of the total NMOG EF detected here, leaving more than $30 \%$ of the NMOG EF unaccounted for in pine smoke (Fig. 6). Akagi et al. (2011) was based primarily on field measurements deemed representative for major BB types. They estimated that about $50 \%$ of the NMOG mass was unknown based on PTR-MS spectra of lab-generated smoke available at the time and provided estimates of unmeasured/unidentified NMOG; however they were not speciated. This work now identifies and quantifies a large fraction of the unknown mass highlighted in that compilation. The fraction of each bin accounted for by the routinely measured compounds or SPECIATE inventory decreases with decreasing volatility (Fig. 6). Thus if the weighting values from SPECIATE are used, the total EF would be mapped to a group of compounds with a significantly higher mean volatility. In particular, IVOCs were almost entirely absent (Fig. 6) based on the applied volatility parameterization; less than $\sim 1 \%$ of the IVOC EF measured in this work for pine smoke was accounted for by the compounds included in the Akagi et al. (2011) compilation (based primarily on field studies) and the SPECIATE inventory. This is likely a conservative esti- 
mate for the fraction of unspeciated emissions given that the largest underestimation occurs at the lower-volatility end of the distribution (Fig. 6), where some fraction of the compounds was also missed by the analytical techniques used in this work. In particular, because smoke collects in the combustion chamber during room burn experiments, losses of sticky or lower-volatility compounds to surfaces or particles can occur (Stockwell et al., 2014).

The distribution of measured IVOCs among the major chemical classes is shown in Fig. 7. For all burns except peat, oxygenates are overwhelmingly dominant, accounting for over $75 \%$ of the IVOC emissions. However, the influence of different oxygenated classes varied from fuel to fuel, with oxygenated aromatics constituting nearly $70 \%$ of the IVOC EF in pine smoke. These compounds were primarily measured by PTR-TOFMS, which thus explains the very large difference in the fraction of IVOCs measured by PTR-TOFMS and GC $\times$ GC-TOFMS for pine smoke (Table 1). IVOCs from straw and spruce include a higher relative fraction of furans and oxygenated aliphatics (which was mostly bornyl acetate in spruce smoke). In contrast, only $53 \%$ of the IVOCs detected in peat smoke were oxygenated. IVOCs in this burn comprised a higher fraction of aromatic and aliphatic HCs than observed in other fuels (Fig. 7). The high fraction of oxygenated IVOCs in BB emissions stands in stark contrast to IVOCs emitted from fossil-fuel combustion, which has generally been measured as (or assumed to be) almost entirely hydrocarbons, particularly alkanes (Zhao et al., 2014; Presto et al., 2009; Tkacik et al., 2012). Our FLAME-4 measurements, however, did not include gas-phase measurements of polycyclic aromatic hydrocarbons (PAHs) larger than acenaphthylene, which have been widely measured in BB emissions (Dhammapala et al., 2007; Hall et al., 2012; Hays et al., 2002; Jenkins et al., 1996; Schauer et al., 2001; Singh et al., 2013). In pine wood smoke, for example, Schauer et al. (2001) reported a total EF for gaseous PAHs larger than acenaphthylene of $0.045 \mathrm{~g} \mathrm{~kg}^{-1}$, which is $\sim 1 \%$ of the total IVOC EF measured from pine smoke in this work.

\subsubsection{SOA yields}

To model BB SOA formation, the propensity of observed compounds to form SOA needs to be known. In most widely used models, SOA formation is based on SOA yields (mass of SOA formed/mass of precursor reacted) determined from smog chamber studies (e.g., as described in Barsanti et al., 2013). An alternative approach is to use a semi-explicit gasphase chemical mechanism to predict the oxidation products of individual NMOG precursors and calculate the gasparticle partitioning of the oxidation products directly. This latter approach was applied by Derwent et al. (2010), who determined the SOA formation potential of 113 anthropogenic NMOGs using the Master Chemical Mechanism v3.1; SOA formation potentials were reported relative to toluene. Re-
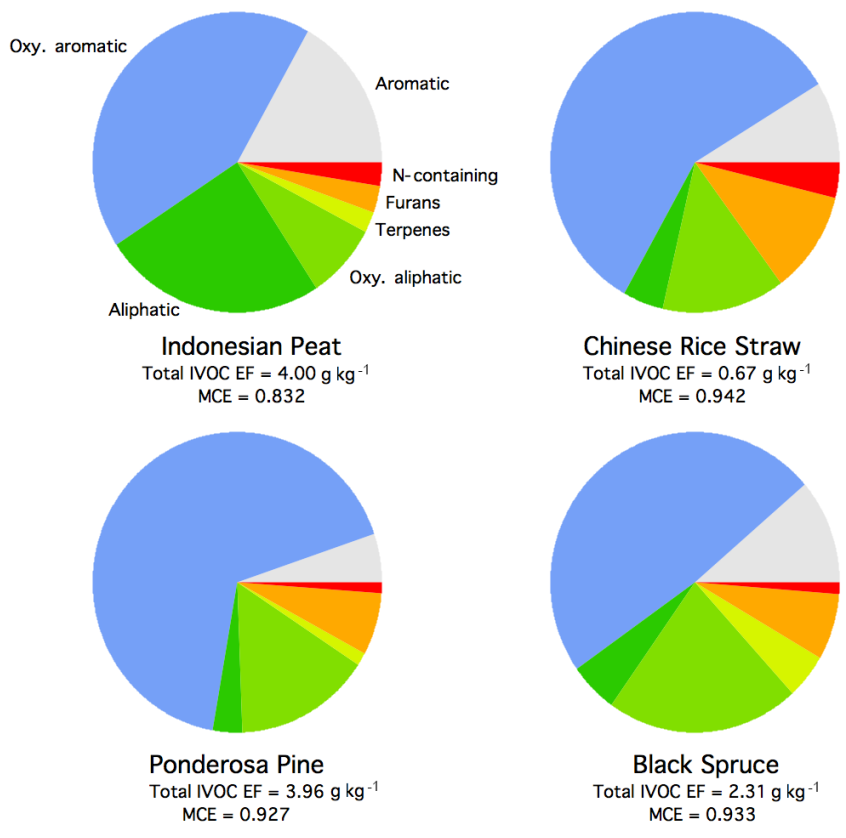

Chinese Rice Straw Total IVOC EF $=0.67 \mathrm{~g} \mathrm{~kg}^{-1}$ $\mathrm{MCE}=0.942$

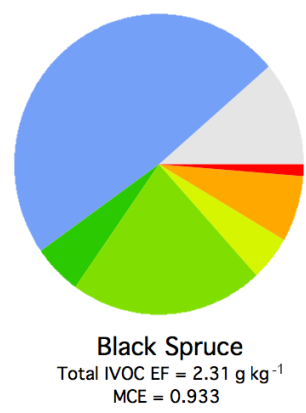

Figure 7. Distribution of intermediate-volatility compounds among the major compound classes.

cently Gilman et al. (2015) used the model-derived SOA potentials from Derwent et al. (2010) to evaluate potential SOA formation from BB emissions. Aromatic compounds contributed most of the SOA formation potential from BB emissions: $18-41 \%$ from aromatic hydrocarbons and 50$75 \%$ from oxygenated aromatic compounds (e.g., benzaldehyde and phenol derivatives) depending on the fuel. The SOA formation potential from monoterpenes using this approach was notably low (factor of 5 less than toluene); Gilman et al. (2015) conducted a sensitivity study and determined the monoterpene contribution was still minimal even when the SOA yield potential for monoterpenes was increased 10 -fold.

In the study by Gilman et al. (2015), <37\% of the compounds overlapped with those reported in Derwent et al. (2010); thus assumptions had to be made regarding representative compounds (and thus representative SOA formation potentials) for nearly two-thirds of the compounds relevant for BB. The majority of the non-aromatic compounds were assigned SOA formation potentials $\leq 1 \%$ that of toluene. Ideally, modeled SOA formation potentials would be available for the specific compounds of interest, and those SOA formation potentials would be compared with smog chamber SOA yield data. For the compounds measured in this work, an extensive literature search was performed to determine the extent of published SOA yield data. For the top 100 compounds from each fuel, which account for $\sim 90 \%$ of the total NMOG EF for each fuel (87-91\%), the measured EF was scaled by the corresponding rate constant for reaction with $\mathrm{OH}$ to emphasize the most reactive compounds and by carbon number as a rough proxy 
for potential SOA contribution. These scaled EFs are hereafter termed "reactive carbon". Measured OH rate coefficients were used where available (Calvert et al., 2015); otherwise values were estimated using the EPA's estimation program AOPWIN (v1.92, U.S. EPA Estimation Programs Interface Suite, 2014), a tool that is based on standard structurereactivity relationships (Atkinson, 1987; Kwok and Atkinson, 1995). Although a few unknown compounds were present in the top 100 compounds, they were not included in this analysis due to the inability to estimate reasonable $\mathrm{OH}$ reaction rate constants. Assuming a generic rate constant of $1 \times 10^{-11} \mathrm{~cm}^{3}$ molecules ${ }^{-1} \mathrm{~s}^{-1}$, the unknown compounds contributed less than $5 \%$ to the total reactive carbon of the top 100 compounds, and thus their omission should not significantly impact the results. We have also omitted the PTR-TOFMS-derived MT EF for spruce smoke due to the suspected interference of bornyl acetate (see Sect. 3.2.2). Compounds were then sorted by the number of publications reporting an SOA yield via OH-radical oxidation (as of May 2016); classifications and corresponding literature references are provided in Table S2. Results are shown in the pie charts of Figs. 8 and 9 for pine and straw smoke, respectively (Figs. S9 and S10 for spruce and peat smoke), illustrating that only $12-22 \%$ of the reactive carbon is associated with very well studied compounds (5+ publications). Such compounds include toluene, $m$-xylene, $\alpha$-pinene, and isoprene. In contrast, between $55 \%$ (pine) and $77 \%$ (straw) of the reactive carbon is associated with compounds for which SOA yields are unknown or understudied (0-1 publications). These fractions could increase appreciably if the neglected unknown compounds are significantly more reactive than assumed above, as SOA yields likely have not been assessed for compounds that could not be identified in this work. Of the understudied compounds, those most likely to form SOA following reaction with $\mathrm{OH}$ radical are outlined in gray in the pie charts of Figs. 8, 9, S9, and S10; these understudied potential precursors constitute between $22 \%$ (peat) and $56 \%$ (straw) of the included reactive carbon for each burn. Therefore, even with improved speciation measurements, critical data for modeling BB SOA formation are missing for a significant fraction of the potentially reactive material.

Many of the understudied potential precursors are furan derivatives and polyunsaturated aliphatic hydrocarbons; only $\sim 10 \%$ (peat) to $28 \%$ (straw) of the reactive carbon contributed by understudied precursors is attributed to aromatic compounds. Thus the largest gaps in known SOA yields relevant for BB are associated with non-aromatic compounds (furans notwithstanding). To better identify specific candidates for future smog chamber studies, the top 10 understudied potential precursors are shown in the corresponding bar charts as a percentage of the reactive carbon included in the gray-outlined wedge (Figs. 8, 9, S9, and S10). For all four fuels, furan derivatives account for 3-5 of the top 10 understudied compounds. Furfural, 2-methyl furan, 2-furan methanol, and 2-hydroxy-3-methyl-2-cyclopentenone (tentatively iden-

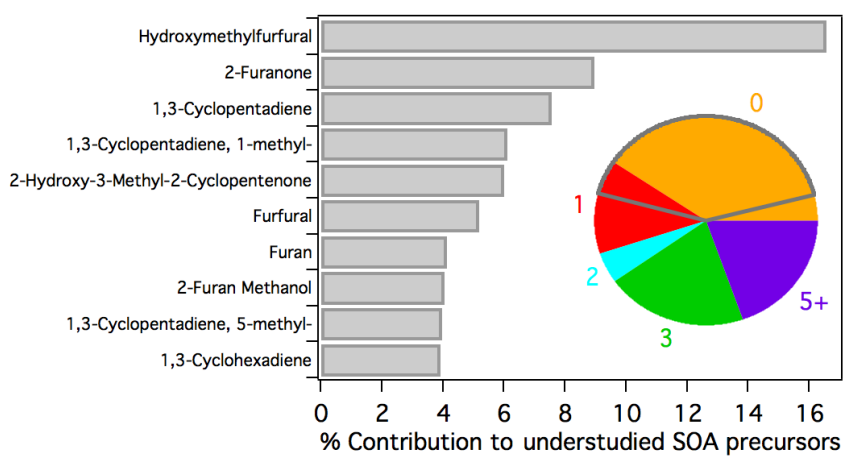

Figure 8. Assessment of SOA yields for compounds detected in the ponderosa pine fire. Pie chart: classification of reactive carbon (see text) by the number of publications reporting an SOA yield following hydroxyl radical oxidation. The gray-outlined wedge represents the understudied compounds with the greatest potential to form SOA. Bar chart: percent contribution of the top 10 compounds included in the gray wedge.

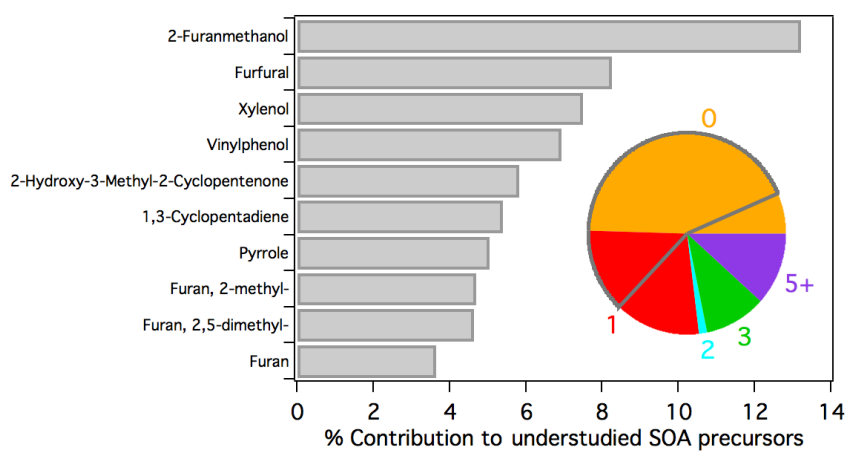

Figure 9. As in Fig. 8 but for a Chinese rice straw fire.

tified by PTR-TOFMS) are common to the top 10 lists for all fuels, although 1,3-cyclopentadiene is present for three of the burns. Given the ubiquity and potential importance of these compounds, future smog chamber experiments with these species may significantly help to narrow knowledge gaps regarding SOA yields of BB emissions.

\section{Conclusions}

Data collected from a unique combination of four instrumental approaches deployed during FLAME-4 have been compared to evaluate the compositional space and calculated EFs accessed by each instrument and to provide comprehensive BB gas-phase emission profiles for four sampled fuels. OP-FTIR has the least amount of sampling artifacts but very limited ability to probe high MW species. PTR-TOFMS with a heated sample line may be best for detecting the lowest-volatility and most polar compounds, but it has significant limitations for compound quantification and identification, and additionally is unable to detect sat- 
urated hydrocarbons. We further found evidence for significant interference in the determination of monoterpene EFs by PTR-TOFMS due to bornyl acetate in spruce smoke and by $\mathrm{C}_{6} \mathrm{H}_{8}$ compounds from non-monoterpene-emitting fuels. As a result, monoterpene EFs calculated using the protonated parent ion $(\mathrm{m} / \mathrm{z}, 137)$ displayed better, though still variable, agreement with the cumulative GC $\times$ GC-TOFMSderived monoterpene $\mathrm{EF}$ than the commonly used fragment ion $(m / z 81)$. GC $\times$ GC-TOFMS can speciate numerous various isomers, but sticky compounds or compounds that break through cartridges may not be detected or may be underestimated. WAS does not suffer from breakthrough but is limited to relatively more volatile compounds than cartridge sampling. The major findings of the data analysis are as follows: (1) all of these techniques together were able to positively or tentatively identify the compound structures for $87-92 \%$ of the NMOG EF detected in smoke sampled during FLAME4, with the remaining EF assigned chemical formulas; (2) a general comparison shows that, despite some outliers for specific species or fires, the overall agreement for overlapping species is within the uncertainty $(<\sim 30 \%)$ for any given technique, with no large bias evident; and (3) this allows us to further conclude that each technique contributes a distinctive ability to identify some important subset of the total BB-derived NMOG. Application of a range of instruments is therefore currently necessary for adequately measuring the wide variety of compounds emitted from BB.

Deployment of this suite of instruments during FLAME-4 enabled us to construct a comprehensive database of emission factors for compounds that cover a wider volatility range than traditionally measured. Although light compounds (carbon number $\leq 3$ ) constituted $40-50 \%$ of the total NMOG EF, a significant fraction (6-11\%) of the observed BB emissions were attributed to IVOCs, which are generally unaccounted for using the typical measurement approaches. These lowervolatility compounds may be efficient SOA precursors. Further, assessment of BB-relevant SOA yields showed that $<25 \%$ of NMOG emissions can be attributed to compounds with well-characterized SOA yields. Instead, $22-56 \%$ of the reactive carbon was attributed to understudied compounds with the potential to form SOA, among which furan derivatives and polyunsaturated hydrocarbons dominated. Future work is therefore needed to assess the SOA formation potential of some major compounds emitted during BB. Ideal candidates for future smog chamber experiments were identified as a starting point for improving the scientific understanding and estimations of SOA production in smoke plumes.

\section{Data availability}

Raw data and additional data not included in Table S1 or the cited references can be obtained by contacting the corresponding author.

\section{The Supplement related to this article is available online at doi:10.5194/acp-17-1471-2017-supplement.}

Competing interests. The authors declare that they have no conflict of interest.

Acknowledgements. This work was supported by the National Science Foundation (grants AGS-PRF-1231128 and ATM-0936321), NASA Earth Science Division (award NNX14AP45G), and BLM Joint Fire Science Program (grant 14-1-03-44). Betsy Stone and Thilina Jayarathne (University of Iowa) are thanked for providing the organic aerosol concentrations.

Edited by: A. Carlton

Reviewed by: two anonymous referees

\section{References}

Akagi, S. K., Yokelson, R. J., Wiedinmyer, C., Alvarado, M. J., Reid, J. S., Karl, T., Crounse, J. D., and Wennberg, P. O.: Emission factors for open and domestic biomass burning for use in atmospheric models, Atmos. Chem. Phys., 11, 4039-4072, doi:10.5194/acp-11-4039-2011, 2011.

Akagi, S. K., Craven, J. S., Taylor, J. W., McMeeking, G. R., Yokelson, R. J., Burling, I. R., Urbanski, S. P., Wold, C. E., Seinfeld, J. H., Coe, H., Alvarado, M. J., and Weise, D. R.: Evolution of trace gases and particles emitted by a chaparral fire in California, Atmos. Chem. Phys., 12, 1397-1421, doi:10.5194/acp-12-13972012, 2012.

Alvarado, M. J. and Prinn, R. G.: Formation of ozone and growth of aerosols in young smoke plumes from biomass burning: 1. Lagrangian parcel studies, J. Geophys. Res.-Atmos., 114, D09306, doi:10.1029/2008jd011144, 2009.

Alvarado, M. J., Wang, C., and Prinn, R. G.: Formation of ozone and growth of aerosols in young smoke plumes from biomass burning: 2. Three-dimensional Eulerian studies, J. Geophys. Res.Atmos., 114, D09307, doi:10.1029/2008jd011186, 2009.

Alvarado, M. J., Lonsdale, C. R., Yokelson, R. J., Akagi, S. K., Coe, H., Craven, J. S., Fischer, E. V., McMeeking, G. R., Seinfeld, J. H., Soni, T., Taylor, J. W., Weise, D. R., and Wold, C. E.: Investigating the links between ozone and organic aerosol chemistry in a biomass burning plume from a prescribed fire in California chaparral, Atmos. Chem. Phys., 15, 6667-6688, doi:10.5194/acp15-6667-2015, 2015.

Arnold, S. T., Viggiano, A. A., and Morris, R. A.: Rate Constants and Product Branching Fractions for the Reactions of $\mathrm{H}_{3} \mathrm{O}^{+}$and $\mathrm{NO}^{+}$with $\mathrm{C}_{2}-\mathrm{C}_{12}$ Alkanes, J. Phys. Chem. A, 102, 8881-8887, doi:10.1021/jp9815457, 1998.

Atkinson, R.: A Structure-Activity Relationship for the Estimation of Rate Constants for the Gas-Phase Reactions of Oh Radicals 
with Organic-Compounds, Int. J. Chem. Kinet., 19, 799-828, doi:10.1002/kin.550190903, 1987.

Barsanti, K. C., Carlton, A. G., and Chung, S. H.: Analyzing experimental data and model parameters: implications for predictions of SOA using chemical transport models, Atmos. Chem. Phys., 13, 12073-12088, doi:10.5194/acp-13-12073-2013, 2013.

Bian, Q., May, A. A., Kreidenweis, S. M., and Pierce, J. R.: Investigation of particle and vapor wall-loss effects on controlled wood-smoke smog-chamber experiments, Atmos. Chem. Phys., 15, 11027-11045, doi:10.5194/acp-15-11027-2015, 2015.

Bian, Q., Jathar, S. H., Kodros, J. K., Barsanti, K. C., Hatch, L. E., May, A. A., Kreidenweis, S. M., and Pierce, J. R.: Secondary organic aerosol formation in biomass-burning plumes: Theoretical analysis of lab studies and ambient plumes, Atmos. Chem. Phys. Discuss., doi:10.5194/acp-2016-949, in review, 2016.

Burling, I. R., Yokelson, R. J., Griffith, D. W. T., Johnson, T. J., Veres, P., Roberts, J. M., Warneke, C., Urbanski, S. P., Reardon, J., Weise, D. R., Hao, W. M., and de Gouw, J.: Laboratory measurements of trace gas emissions from biomass burning of fuel types from the southeastern and southwestern United States, Atmos. Chem. Phys., 10, 11115-11130, doi:10.5194/acp10-11115-2010, 2010.

Calvert, J. G., Orlando, J. J., Stockwell, W. R., and Wallington, T. J.: The mechanisms of reactions influencing atmospheric ozone, Oxford University Press, New York, USA, 2015.

Chan, A. W. H., Kautzman, K. E., Chhabra, P. S., Surratt, J. D., Chan, M. N., Crounse, J. D., Kürten, A., Wennberg, P. O., Flagan, R. C., and Seinfeld, J. H.: Secondary organic aerosol formation from photooxidation of naphthalene and alkylnaphthalenes: implications for oxidation of intermediate volatility organic compounds (IVOCs), Atmos. Chem. Phys., 9, 3049-3060, doi:10.5194/acp-9-3049-2009, 2009.

Christian, T. J., Kleiss, B., Yokelson, R. J., Holzinger, R., Crutzen, P. J., Hao, W. M., Shirai, T., and Blake, D. R.: Comprehensive laboratory measurements of biomass-burning emissions: 2. First intercomparison of open-path FTIR, PTR-MS, and GC- MS/FID/ECD, J. Geophys. Res.-Atmos., 109, D02311, doi:10.1029/2003jd003874, 2004.

de Gouw, J. and Warneke, C.: Measurements of volatile organic compounds in the earths atmosphere using proton-transferreaction mass spectrometry, Mass Spectrom. Rev., 26, 223-257, 10.1002/mas.20119, 2007.

Derwent, R. G., Jenkin, M. E., Utembe, S. R., Shallcross, D. E., Murrells, T. P., and Passant, N. R.: Secondary organic aerosol formation from a large number of reactive manmade organic compounds, Sci. Total Environ., 408, 3374-3381, doi:10.1016/j.scitotenv.2010.04.013, 2010.

Desalmand, F. and Serpolay, R.: Some specific features of the aerosol-particle concentrations during the dry season and during a bushfire event in West-Africa, Atmos. Environ., 19, 1535$1543,1985$.

Dhammapala, R., Claiborn, C., Jimenez, J., Corkill, J., Gullett, B., Simpson, C., and Paulsen, M.: Emission factors of PAHs, methoxyphenols, levoglucosan, elemental carbon and organic carbon from simulated wheat and Kentucky bluegrass stubble burns, Atmos. Environ., 41, 2660-2669, doi:10.1016/j.atmosenv.2006.11.023, 2007.

Donahue, N. M., Robinson, A. L., and Pandis, S. N.: Atmospheric organic particulate matter: From smoke to secondary organic aerosol, Atmos. Environ., 43, 94-106, doi:10.1016/j.atmosenv.2008.09.055, 2009.

Environmental Protection Agency (EPA): SPECIATE Version 4.2, available at: http://www3.epa.gov/ttn/chief/software/speciate/ index.html (last access: 15 October 2015), 2008.

Flannigan, M. D., Krawchuk, M. A., de Groot, W. J., Wotton, B. M., and Gowman, L. M.: Implications of changing climate for global wildland fire, Int. J. Wildland Fire, 18, 483-507, doi:10.1071/WF08187, 2009.

Forrister, H., Liu, J., Scheuer, E., Dibb, J., Ziemba, L., Thornhill, K. L., Anderson, B., Diskin, G., Perring, A. E., Schwarz, J. P., Campuzano-Jost, P., Day, D. A., Palm, B. B., Jimenez, J. L., Nenes, A., and Weber, R. J.: Evolution of brown carbon in wildfire plumes, Geophys. Res. Lett., 42, 4623-4630, doi:10.1002/2015g1063897, 2015.

Garcia-Hurtado, E., Pey, J., Borras, E., Sanchez, P., Vera, T., Carratala, A., Alastuey, A., Querol, X., and Vallejo, V. R.: Atmospheric PM and volatile organic compounds released from Mediterranean shrubland wildfires, Atmos. Environ., 89, 85-92, doi:10.1016/j.atmosenv.2014.02.016, 2014.

Gilman, J. B., Lerner, B. M., Kuster, W. C., Goldan, P. D., Warneke, C., Veres, P. R., Roberts, J. M., de Gouw, J. A., Burling, I. R., and Yokelson, R. J.: Biomass burning emissions and potential air quality impacts of volatile organic compounds and other trace gases from fuels common in the US, Atmos. Chem. Phys., 15, 13915-13938, doi:10.5194/acp-15-13915-2015, 2015.

Grieshop, A. P., Logue, J. M., Donahue, N. M., and Robinson, A. L.: Laboratory investigation of photochemical oxidation of organic aerosol from wood fires 1: measurement and simulation of organic aerosol evolution, Atmos. Chem. Phys., 9, 1263-1277, doi:10.5194/acp-9-1263-2009, 2009.

Hall, D., Wu, C. Y., Hsu, Y. M., Stormer, J., Engling, G., Capeto, K., Wang, J., Brown, S., Li, H. W., and Yu, K. M.: PAHs, carbonyls, VOCs and $\mathrm{PM}_{2.5}$ emission factors for pre-harvest burning of Florida sugarcane, Atmos. Environ., 55, 164-172, doi:10.1016/j.atmosenv.2012.03.034, 2012.

Hatch, L. E., Luo, W., Pankow, J. F., Yokelson, R. J., Stockwell, C. E., and Barsanti, K. C.: Identification and quantification of gaseous organic compounds emitted from biomass burning using two-dimensional gas chromatography-time-of-flight mass spectrometry, Atmos. Chem. Phys., 15, 1865-1899, doi:10.5194/acp15-1865-2015, 2015.

Hays, M. D., Geron, C. D., Linna, K. J., Smith, N. D., and Schauer, J. J.: Speciation of gas-phase and fine particle emissions from burning of foliar fuels, Environ. Sci. Technol., 36, 2281-2295, 2002.

Heald, C. L., Coe, H., Jimenez, J. L., Weber, R. J., Bahreini, R., Middlebrook, A. M., Russell, L. M., Jolleys, M., Fu, T.-M., Allan, J. D., Bower, K. N., Capes, G., Crosier, J., Morgan, W. T., Robinson, N. H., Williams, P. I., Cubison, M. J., DeCarlo, P. F., and Dunlea, E. J.: Exploring the vertical profile of atmospheric organic aerosol: comparing 17 aircraft field campaigns with a global model, Atmos. Chem. Phys., 11, 12673-12696, doi:10.5194/acp-11-12673-2011, 2011.

Helmig, D.: Ozone removal techniques in the sampling of atmospheric volatile organic trace gases, Atmos. Environ., 31, 36353651, 1997.

Hennigan, C. J., Miracolo, M. A., Engelhart, G. J., May, A. A., Presto, A. A., Lee, T., Sullivan, A. P., McMeeking, G. R., Coe, 
H., Wold, C. E., Hao, W.-M., Gilman, J. B., Kuster, W. C., de Gouw, J., Schichtel, B. A., Collett Jr., J. L., Kreidenweis, S. M., and Robinson, A. L.: Chemical and physical transformations of organic aerosol from the photo-oxidation of open biomass burning emissions in an environmental chamber, Atmos. Chem. Phys., 11, 7669-7686, doi:10.5194/acp-11-7669-2011, 2011.

Herron-Thorpe, F. L., Mount, G. H., Emmons, L. K., Lamb, B. K., Jaffe, D. A., Wigder, N. L., Chung, S. H., Zhang, R., Woelfle, M. D., and Vaughan, J. K.: Air quality simulations of wildfires in the Pacific Northwest evaluated with surface and satellite observations during the summers of 2007 and 2008, Atmos. Chem. Phys., 14, 12533-12551, doi:10.5194/acp-14-12533-2014, 2014.

Hessl, A. E.: Pathways for climate change effects on fire: Models, data, and uncertainties, Prog. Phys. Geogr., 35, 393-407, doi:10.1177/0309133311407654, 2011.

Hobbs, P. V., Sinha, P., Yokelson, R. J., Christian, T. J., Blake, D. R., Gao, S., Kirchstetter, T. W., Novakov, T., and Pilewskie, P.: Evolution of gases and particles from a savanna fire in South Africa, J. Geophys. Res.-Atmos., 108, 8485, doi:10.1029/2002jd002352, 2003.

Jathar, S. H., Gordon, T. D., Hennigan, C. J., Pye, H. O. T., Pouliot, G., Adams, P. J., Donahue, N. M., and Robinson, A. L.: Unspeciated organic emissions from combustion sources and their influence on the secondary organic aerosol budget in the United States, P. Natl. Acad. Sci. USA, 111, 10473-10478, doi:10.1073/pnas.1323740111, 2014.

Jayarathne, T., Stockwell, C. E., Yokelson, R. J., Nakao, S., and Stone, E. A.: Emissions of Fine Particle Fluoride from Biomass Burning, Environ. Sci. Technol., 48, 12636-12644, doi:10.1021/es502933j, 2014.

Jenkins, B. M., Jones, A. D., Turn, S. Q., and Williams, R. B.: Emission factors for polycyclic aromatic hydrocarbons from biomass burning, Environ. Sci. Technol., 30, 2462-2469, 1996.

Jolleys, M. D., Coe, H., McFiggans, G., Capes, G., Allan, J. D., Crosier, J., Williams, P. I., Allen, G., Bower, K. N., Jimenez, J. L., Russell, L. M., Grutter, M., and Baumgardner, D.: Characterizing the aging of biomass burning organic aerosol by use of mixing ratios: A meta-analysis of four regions, Environ. Sci. Technol., 46, 13093-13102, 2012.

Jordan, A., Haidacher, S., Hanel, G., Hartungen, E., Mark, L., Seehauser, H., Schottkowsky, R., Sulzer, P., and Mark, T. D.: A high resolution and high sensitivity proton-transfer-reaction time-offlight mass spectrometer (PTR-TOF-MS), Int. J. Mass. Spectrom., 286, 122-128, doi:10.1016/j.ijms.2009.07.005, 2009.

Kesselmeier, J. and Staudt, M.: Biogenic volatile organic compounds (VOC): An overview on emission, physiology and ecology, J. Atmos. Chem., 33, 23-88, 1999.

Kim, S., Karl, T., Guenther, A., Tyndall, G., Orlando, J., Harley, P., Rasmussen, R., and Apel, E.: Emissions and ambient distributions of Biogenic Volatile Organic Compounds (BVOC) in a ponderosa pine ecosystem: interpretation of PTR-MS mass spectra, Atmos. Chem. Phys., 10, 1759-1771, doi:10.5194/acp-101759-2010, 2010.

Kwok, E. S. C. and Atkinson, R.: Estimation of Hydroxyl Radical Reaction-Rate Constants for Gas-Phase Organic-Compounds Using a Structure-Reactivity Relationship - an Update, Atmos. Environ., 29, 1685-1695, doi:10.1016/1352-2310(95)00069-B, 1995.
Li, Y., Pöschl, U., and Shiraiwa, M.: Molecular corridors and parameterizations of volatility in the chemical evolution of organic aerosols, Atmos. Chem. Phys., 16, 3327-3344, doi:10.5194/acp16-3327-2016, 2016.

Lim, Y. B. and Ziemann, P. J.: Effects of molecular structure on aerosol yields from $\mathrm{OH}$ radical-initiated reactions of linear, branched, and cyclic alkanes in the presence of $\mathrm{NO}_{x}$, Environ. Sci. Technol., 43, 2328-2334, doi:10.1021/Es803389s, 2009.

Lindinger, W., Hansel, A., and Jordan, A.: Proton-transfer-reaction mass spectrometry (PTR-MS): on-line monitoring of volatile organic compounds at pptv levels, Chem. Soc. Rev., 27, 347-354, doi:10.1039/a827347z, 1998.

Maleknia, S. D., Bell, T. L., and Adams, M. A.: PTRMS analysis of reference and plant-emitted volatile organic compounds, Int. J. Mass. Spectrom., 262, 203-210, doi:10.1016/j.ijms.2006.11.010, 2007.

May, A. A., Lee, T., McMeeking, G. R., Akagi, S., Sullivan, A. P., Urbanski, S., Yokelson, R. J., and Kreidenweis, S. M.: Observations and analysis of organic aerosol evolution in some prescribed fire smoke plumes, Atmos. Chem. Phys., 15, 6323-6335, doi:10.5194/acp-15-6323-2015, 2015.

Mondello, L., Tranchida, P. Q., Dugo, P., and Dugo, G.: Comprehensive two-dimensional gas chromatography-mass spectrometry: A review, Mass Spectrom. Rev., 27, 101-124, doi:10.1002/Mas.20158, 2008.

Naeher, L. P., Brauer, M., Lipsett, M., Zelikoff, J. T., Simpson, C. D., Koenig, J. Q., and Smith, K. R.: Woodsmoke Health Effects: A Review, Inhal. Toxicol., 19, 67-106, doi:10.1080/08958370600985875, 2007.

Ortega, A. M., Day, D. A., Cubison, M. J., Brune, W. H., Bon, D., de Gouw, J. A., and Jimenez, J. L.: Secondary organic aerosol formation and primary organic aerosol oxidation from biomass-burning smoke in a flow reactor during FLAME-3, Atmos. Chem. Phys., 13, 11551-11571, doi:10.5194/acp-1311551-2013, 2013.

Perraud, V., Meinardi, S., Blake, D. R., and Finlayson-Pitts, B. J.: Challenges associated with the sampling and analysis of organosulfur compounds in air using real-time PTR-ToFMS and offline GC-FID, Atmos. Meas. Tech., 9, 1325-1340, doi:10.5194/amt-9-1325-2016, 2016.

Presto, A. A., Miracolo, M. A., Kroll, J. H., Worsnop, D. R., Robinson, A. L., and Donahue, N. M.: Intermediate-Volatility Organic Compounds: A Potential Source of Ambient Oxidized Organic Aerosol, Environ. Sci. Technol., 43, 4744-4749, doi:10.1021/Es803219q, 2009.

Reddington, C. L., Spracklen, D. V., Artaxo, P., Ridley, D. A., Rizzo, L. V., and Arana, A.: Analysis of particulate emissions from tropical biomass burning using a global aerosol model and long-term surface observations, Atmos. Chem. Phys., 16, 1108311106, doi:10.5194/acp-16-11083-2016, 2016.

Reid, J. S., Koppmann, R., Eck, T. F., and Eleuterio, D. P.: A review of biomass burning emissions part II: intensive physical properties of biomass burning particles, Atmos. Chem. Phys., 5, 799825, doi:10.5194/acp-5-799-2005, 2005.

Robinson, A. L., Donahue, N. M., Shrivastava, M. K., Weitkamp, E. A., Sage, A. M., Grieshop, A. P., Lane, T. E., Pierce, J. R., and Pandis, S. N.: Rethinking organic aerosols: Semivolatile emissions and photochemical aging, Science, 315, 1259-1262, doi:10.1126/science.1133061, 2007. 
Schauer, J. J., Kleeman, M. J., Cass, G. R., and Simoneit, B. R. T.: Measurement of emissions from air pollution sources. 3. C1-C-29 organic compounds from fireplace combustion of wood, Environ. Sci. Technol., 35, 1716-1728, 2001.

Shiraiwa, M., Berkemeier, T., Schilling-Fahnestock, K. A., Seinfeld, J. H., and Pöschl, U.: Molecular corridors and kinetic regimes in the multiphase chemical evolution of secondary organic aerosol, Atmos. Chem. Phys., 14, 8323-8341, doi:10.5194/acp-14-8323-2014, 2014.

Simpson, I. J., Blake, N. J., Barletta, B., Diskin, G. S., Fuelberg, H. E., Gorham, K., Huey, L. G., Meinardi, S., Rowland, F. S., Vay, S. A., Weinheimer, A. J., Yang, M., and Blake, D. R.: Characterization of trace gases measured over Alberta oil sands mining operations: 76 speciated $\mathrm{C}_{2}-\mathrm{C}_{10}$ volatile organic compounds (VOCs), $\mathrm{CO}_{2}, \mathrm{CH}_{4}, \mathrm{CO}, \mathrm{NO}, \mathrm{NO}_{2}, \mathrm{NO}_{y}, \mathrm{O}_{3}$ and $\mathrm{SO}_{2}$, Atmos. Chem. Phys., 10, 11931-11954, doi:10.5194/acp-10-11931-2010, 2010.

Simpson, I. J., Akagi, S. K., Barletta, B., Blake, N. J., Choi, Y., Diskin, G. S., Fried, A., Fuelberg, H. E., Meinardi, S., Rowland, F. S., Vay, S. A., Weinheimer, A. J., Wennberg, P. O., Wiebring, P., Wisthaler, A., Yang, M., Yokelson, R. J., and Blake, D. R.: Boreal forest fire emissions in fresh Canadian smoke plumes: $\mathrm{C}_{1}-\mathrm{C}_{10}$ volatile organic compounds (VOCs), $\mathrm{CO}_{2}, \mathrm{CO}, \mathrm{NO}_{2}$, $\mathrm{NO}, \mathrm{HCN}$ and $\mathrm{CH}_{3} \mathrm{CN}$, Atmos. Chem. Phys., 11, 6445-6463, doi:10.5194/acp-11-6445-2011, 2011.

Simpson, I. J., Aburizaiza, O. S., Siddique, A., Barletta, B., Blake, N. J., Gartner, A., Khwaja, H., Meinardi, S., Zeb, J., and Blake, D. R.: Air Quality in Mecca and Surrounding Holy Places in Saudi Arabia During Hajj: Initial Survey, Environ. Sci. Technol., 48, 8529-8537, doi:10.1021/es5017476, 2014.

Singh, D. P., Gadi, R., Mandal, T. K., Saud, T., Saxena, M., and Sharma, S. K.: Emissions estimates of PAH from biomass fuels used in rural sector of Indo-Gangetic Plains of India, Atmos. Environ., 68, 120-126, doi:10.1016/j.atmosenv.2012.11.042, 2013.

Stockwell, C. E., Yokelson, R. J., Kreidenweis, S. M., Robinson, A. L., DeMott, P. J., Sullivan, R. C., Reardon, J., Ryan, K. C., Griffith, D. W. T., and Stevens, L.: Trace gas emissions from combustion of peat, crop residue, domestic biofuels, grasses, and other fuels: configuration and Fourier transform infrared (FTIR) component of the fourth Fire Lab at Missoula Experiment (FLAME4), Atmos. Chem. Phys., 14, 9727-9754, doi:10.5194/acp-149727-2014, 2014.

Stockwell, C. E., Veres, P. R., Williams, J., and Yokelson, R. J.: Characterization of biomass burning emissions from cooking fires, peat, crop residue, and other fuels with high-resolution proton-transfer-reaction time-of-flight mass spectrometry, Atmos. Chem. Phys., 15, 845-865, doi:10.5194/acp-15-845-2015, 2015.

Tani, A., Hayward, S., and Hewitta, C. N.: Measurement of monoterpenes and related compounds by proton transfer reaction-mass spectrometry (PTR-MS), Int. J. Mass. Spectrom., 223, 561-578, doi:10.1016/S1387-3806(02)00880-1, 2003.

Tilman, D., Fargione, J., Wolff, B., D'Antonio, C., Dobson, A., Howarth, R., Schindler, D., Schlesinger, W. H., Simberloff, D., and Swackhamer, D.: Forecasting agriculturally driven global environmental change, Science, 292, 281-284, doi:10.1126/science.1057544, 2001.

Tinling, M. A., West, J. J., Cascio, W. E., Kilaru, V., and Rappold, A. G.: Repeating cardiopulmonary health effects in rural North
Carolina population during a second large peat wildfire, Environ. Health, 15, 1-12, doi:10.1186/s12940-016-0093-4, 2016.

Tkacik, D. S., Presto, A. A., Donahue, N. M., and Robinson, A. L.: Secondary Organic Aerosol Formation from Intermediate-Volatility Organic Compounds: Cyclic, Linear, and Branched Alkanes, Environ. Sci. Technol., 46, 8773-8781, doi:10.1021/es301112c, 2012.

Vakkari, V., Kerminen, V. M., Beukes, J. P., Tiitta, P., van Zyl, P. G., Josipovic, M., Venter, A. D., Jaars, K., Worsnop, D. R., Kulmala, M., and Laakso, L.: Rapid changes in biomass burning aerosols by atmospheric oxidation, Geophys. Res. Lett., 41, 2644-2651, doi:10.1002/2014g1059396, 2014.

Viswanathan, S., Eria, L., Diunugala, N., Johnson, J., and McClean, C.: An analysis of effects of San Diego wildfire on Air quality, J. Air Waste Manage., 56, 56-67, doi:10.1080/10473289.2006.10464439, 2006.

von Rudloff, E.: Seasonal Variation in the Terpenes of the Foliage of Black Spruce, Phytochemistry, 14, 1695-1699, 1975.

Warneke, C., De Gouw, J. A., Kuster, W. C., Goldan, P. D., and Fall, R.: Validation of atmospheric VOC measurements by proton-transfer-reaction mass spectrometry using a gaschromatographic preseparation method, Environ. Sci. Technol., 37, 2494-2501, doi:10.1021/es026266i, 2003.

Warneke, C., Roberts, J. M., Veres, P., Gilman, J., Kuster, W. C., Burling, I., Yokelson, R., and de Gouw, J. A.: VOC identification and inter-comparison from laboratory biomass burning using PTR-MS and PIT-MS, Int. J. Mass. Spectrom., 303, 6-14, doi:10.1016/j.ijms.2010.12.002, 2011.

Westerling, A. L., Hidalgo, H. G., Cayan, D. R., and Swetnam, T. W.: Warming and earlier spring increase western US forest wildfire activity, Science, 313, 940-943, doi:10.1126/science.1128834, 2006.

Yokelson, R. J., Christian, T. J., Karl, T. G., and Guenther, A.: The tropical forest and fire emissions experiment: laboratory fire measurements and synthesis of campaign data, Atmos. Chem. Phys., 8, 3509-3527, doi:10.5194/acp-8-3509-2008, 2008.

Yokelson, R. J., Crounse, J. D., DeCarlo, P. F., Karl, T., Urbanski, S., Atlas, E., Campos, T., Shinozuka, Y., Kapustin, V., Clarke, A. D., Weinheimer, A., Knapp, D. J., Montzka, D. D., Holloway, J., Weibring, P., Flocke, F., Zheng, W., Toohey, D., Wennberg, P. O., Wiedinmyer, C., Mauldin, L., Fried, A., Richter, D., Walega, J., Jimenez, J. L., Adachi, K., Buseck, P. R., Hall, S. R., and Shetter, R.: Emissions from biomass burning in the Yucatan, Atmos. Chem. Phys., 9, 5785-5812, doi:10.5194/acp-9-5785-2009, 2009.

Yokelson, R. J., Burling, I. R., Gilman, J. B., Warneke, C., Stockwell, C. E., de Gouw, J., Akagi, S. K., Urbanski, S. P., Veres, P., Roberts, J. M., Kuster, W. C., Reardon, J., Griffith, D. W. T., Johnson, T. J., Hosseini, S., Miller, J. W., Cocker III, D. R., Jung, H., and Weise, D. R.: Coupling field and laboratory measurements to estimate the emission factors of identified and unidentified trace gases for prescribed fires, Atmos. Chem. Phys., 13, 89-116, doi:10.5194/acp-13-89-2013, 2013.

Yue, X., Mickley, L. J., Logan, J. A., Hudman, R. C., Martin, M. V., and Yantosca, R. M.: Impact of 2050 climate change on North American wildfire: consequences for ozone air quality, Atmos. Chem. Phys., 15, 10033-10055, doi:10.5194/acp-1510033-2015, 2015. 
Zhao, Y., Hennigan, C. J., May, A. A., Tkacik, D. S., de Gouw, J. A., Gilman, J. B., Kuster, W. C., Borbon, A., and Robinson, A. L.: Intermediate-Volatility Organic Compounds: A Large Source of Secondary Organic Aerosol, Environ. Sci. Technol., 48, 1374313750, doi:10.1021/es5035188, 2014.
Ziemann, P. J. and Atkinson, R.: Kinetics, products, and mechanisms of secondary organic aerosol formation, Chem. Soc. Rev., 41, 6582-6605, doi:10.1039/c2cs35122f, 2012. 